NBER WORKING PAPER SERIES

\title{
TRADE REFORMS AND MARKET SELECTION: EVIDENCE FROM MANUFACTURING PLANTS IN COLOMBIA
}

\author{
Marcela Eslava \\ John C. Haltiwanger \\ Adriana D. Kugler \\ Maurice Kugler \\ Working Paper 14935 \\ http://www.nber.org/papers/w14935 \\ NATIONAL BUREAU OF ECONOMIC RESEARCH \\ 1050 Massachusetts Avenue \\ Cambridge, MA 02138 \\ April 2009
}

We thank Diana Hincapie, Rafael Santos, and Camilo Morales for excellent research assistance, and Roberto Alvarez, Mary Amiti, Orazio Attanasio, Sebastian Edwards, Ricardo Hausmann, Larry Kleinman, Ralf Martin, Alejandro Micco, Nina Pavcnik, Carmen Pages, Dani Rodrik, Chad Syverson and John van Reenen as well as participants at numerous seminars and conferences. Support was provided by NSF Grant SES-0617816, the Tinker Foundation, the IDB, and a GEAR grant from the University of Houston. We are also grateful to the National Planning Department for providing data on tariffs, and to DANE for access to the Manufacturing Survey and advice about its use. The views expressed herein are those of the author(s) and do not necessarily reflect the views of the National Bureau of Economic Research.

NBER working papers are circulated for discussion and comment purposes. They have not been peerreviewed or been subject to the review by the NBER Board of Directors that accompanies official NBER publications.

(C) 2009 by Marcela Eslava, John C. Haltiwanger, Adriana D. Kugler, and Maurice Kugler. All rights reserved. Short sections of text, not to exceed two paragraphs, may be quoted without explicit permission provided that full credit, including $(\odot$ notice, is given to the source. 
Trade Reforms and Market Selection: Evidence from Manufacturing Plants in Colombia Marcela Eslava, John C. Haltiwanger, Adriana D. Kugler, and Maurice Kugler

NBER Working Paper No. 14935

April 2009

JEL No. F43,L25,O47

\begin{abstract}
$\underline{\text { ABSTRACT }}$
We use plant output and input prices to decompose the profit margin into four parts: productivity, demand shocks, mark-ups and input costs. We find that each of these market fundamentals are important in explaining plant exit. We then use variation across sectors in tariff changes after the Colombian trade reform to assess whether the impact of market fundamentals on plant exit changed with increased international competition. We find that greater international competition magnifies the impact of productivity, and other market fundamentals, on plant exit. A dynamic simulation that compares the distribution of productivity with and without the trade reform shows that improvements in market selection from trade reform help to weed out the least productive plants and increase average productivity. In addition, we find that trade liberalization increases productivity of incumbent plants and improves the allocation of activity within industries.
\end{abstract}

Marcela Eslava

Universidad de Los Andes

Carrera 1 Este No 18 A -70. Bloque C

Bogota, Colombia

meslava@uniandes.edu.co

John C. Haltiwanger

Department of Economics

University of Maryland

College Park, MD 20742

and NBER

haltiwan@econ.umd.edu

\author{
Adriana D. Kugler \\ University of Houston \\ Department of Economics \\ 204 McElhinney Hall \\ Houston, TX 77204-5019 \\ and NBER \\ adkugler@uh.edu \\ Maurice Kugler \\ Harvard University \\ Center for International Development \\ 79 JFK Street \\ Cambridge, MA 02138 \\ and \\ Wilfrid Laurier University \\ maurice_kugler@harvard.edu
}




\section{Introduction}

It is clear that an important means by which market economies restructure and innovate is through the entry and exit of establishments. Consistent with that view, in economies like the U.S., the entry and exit process has been identified as an important component of aggregate productivity growth. Aggregate productivity growth is achieved, in part, by the ongoing market selection process that involves the exit of low productivity businesses and the entry of businesses that exhibit either higher relative productivity at entry or rapid productivity growth in their first few years. ${ }^{1}$

Given the importance of business turnover for productivity growth, rigid market institutions and concentrated market structures can be expected to affect aggregate productivity by raising barriers to both entry and exit. Barriers on either margin are likely to reduce the overall pace of firm and establishment turnover and to generate misallocation of activity in the economy. Recent theoretical models, indeed, show that poor market institutions (including trade barriers) generate misallocation by introducing idiosyncratic distortions to profitability (see Banerjee and Duflo (2005), Hsieh and Klenow (2009), Restuccia and Rogerson (2008), and Bartelsman et al. (2008)).

Surprisingly, early evidence for developing economies shows that the pace of establishment turnover is typically not that different from that observed for industrialized economies. $^{2}$ This is at odds with the idea that developing economies, which are typically subject to more restrictive institutions, should have a slower pace of reallocation. On the other hand, recent findings from both emerging and transition economies suggest that market reforms improve allocative efficiency (e.g., Bartelsman et al. (2008), Eslava et al. (2004, 2006, 2009)). By contrast to these recent studies, in this paper, we explore the link between market selection and a particular area of market reform - namely, trade liberalization.

Trade liberalization has been a core component of market reforms in developing economies and, in particular, in Latin America. Trade liberalization could affect plant exits and productivity through a number of channels. First, as Pavcnik (2002) and others argue, increased international competition may induce incumbent firms to become more productive. ${ }^{3}$ Second, Melitz (2003) shows that trade liberalization could force

\footnotetext{
${ }^{1}$ See, e.g., Baily, Campbell and Hulten (1992), Bartelsman and Doms (2000), Foster, Haltiwanger and Krizan (2001), Foster, Haltiwanger and Syverson (2008), and Olley and Pakes (1996).

${ }^{2}$ See, e.g., Bartelsman et al. (2008) and Tybout (2000).

${ }^{3} \mathrm{~A}$ number of studies find that productivity of incumbent producers increases after trade opening, including: Levinsohn (1993) for Turkey, Harrison (1994) for Cote d'Ivoire, Tybout and Westbrook
} 
lower productivity firms out of the market, cutting off the lower tail of the productivity distribution. In a related vein, Restuccia and Rogerson (2008) show that less regulated environments enhance the role of productivity as a determinant of plant survival. In our empirical analysis we focus on the direct and indirect impacts of trade on exits, as suggested by the recent literature.

An important aspect of trade opening in Colombia is that it varied widely across sectors. This between-sector, within country, variation reflects substantial differences in tariff changes across different sectors, as well as substantial differences in initial tariff levels. The large variation in the extent of trade opening across sectors, along with rich longitudinal establishment-level data for the manufacturing sector of Colombia provides a unique opportunity to explore the impact of trade liberalization on market selection. Not only do we explore the direct impact of the reduction of trade barriers on exits, but we also explore how reduced trade barriers affected the role of market fundamentals on plant exits in Colombia. In particular, we explore how trade liberalization affected the role of idiosyncratic (i.e., plant-level) total factor productivity, demand shocks, markups and cost variation. Finally, we explore whether increased exit of low productivity plants following trade reform leads to increases in average productivity. ${ }^{4}$

A novel feature of our analysis is the separate measurement of physical productivity (rather than revenue-based productivity), idiosyncratic demand, mark-ups and input costs, which allows us to evaluate separately the impact that each of these determinants has on plant exit. By contrast, previous analyses of exit patterns after trade liberalization rely on reduced form plant characteristics related to survival, such as size and age, rather than market fundamentals which directly determine exit (e.g., Gibson and Harris (1996), Baggs (2005), and Bernard and Jensen (2007)). Unlike previous analyses, we are able to measure these fundamentals separately because the Colombian Manufacturing Survey allows to construct plant-level prices of both inputs and outputs. This unique feature of (1995) for Mexico, Pavcnik (2002) for Chile, Trefler (2004) for Canada, Topalova (2004) for India, and Fernandes (2007) for Colombia.

${ }^{4}$ In our earlier work (i.e., Eslava et al. (2006)), we show that some market fundamentals became more important determinants of plant exit in the 1990s relative to the 1980s in Colombia. The 1990s was a period of market reforms on many dimensions including trade, financial market, labor market, privatization, and tax reforms. In contrast to this paper, our earlier work made no attempt to identify the impact of particular reforms on market selection, and did not exploit the cross-sectional variation of regulations. Moreover, our earlier work also had less detailed measures of fundamentals (e.g., we lacked a measure of market power). Finally, our earlier work did not look at the implications of selection for average productivity, nor did it explore some of the alternative channels of the impact of trade reform on aggregate productivity that we study here. 
the data is useful for our purposes in several ways. First, we are able to deflate output with plant-specific deflators, leading to a measure of TFP that has been stripped of idiosyncratic demand effects. Our approach contrasts with most of the literature, where the measurement of TFP uses plant-level revenue deflated with a sector-level price index. Given within sector price variability, the standard estimation of TFP confounds high physical efficiency and high prices. Second, we are able to estimate demand shocks at the plant level due to the availability of plant-level output prices. In our estimation of the demand process, we also allow mark-ups to vary across plants. Consistent with theories of market selection, we find that plants with higher productivity, those facing lower input prices, and those subject to positive demand shocks and with more inelastic demands, are less likely to exit.

Moreover, we find that market fundamentals (with the exception of the mark-up) become more important in determining plant survival, as competition increases due to trade opening. In particular, we find that the marginal effect of productivity on exit increases in sectors facing declines in tariffs. Given improved market selection, we explore the implications for aggregate productivity by conducting a dynamic counterfactual simulation of the exit process under two scenarios: one with the actual tariff levels and another one leaving the tariffs at their initial, 1984, levels. We find an increase in average plant-level productivity of about $3.3 \mathrm{log}$ points due to improved market selection with the actual tariffs relative to the 1984 tariffs. This analysis is novel, as previous studies do not explore the impact of increased selectivity in plant exits on average productivity after trade opening. ${ }^{5}$

In addition, we consider some alternative channels through which trade liberalization can affect productivity to put our findings on market selection in context. In particular, following Pavcnik (2002), we use a differences-in-differences specification to quantify the impact of trade reform on within plant productivity growth for continuing plants. Our results reinforce Pavcnik's (2002) main finding that trade opening increases withinplant productivity growth, making use of the improved measures of trade opening and productivity that are available for Colombia. In particular, we use tariffs that vary within-sector and over time, while in the Chilean case studied by Pavcnik tariffs varied only over time so that tariff reductions had to be captured through time dummies in her analysis. In addition, our TFP measure captures physical productivity rather than a revenue-based measure of productivity which combines withing sector differences in

\footnotetext{
${ }^{5}$ See, e.g., Gibson and Harris (1996) for New Zeland's trade liberalization; Head and Ries (1999) and Baggs (2005) for Canada and NAFTA; Bernard and Jensen(2007) for FDI in the United States.
} 
prices and physical efficiency effects. Another channel we explore is whether trade opening strengthens the relationship between market size and productivity as discussed by Olley and Pakes (1996) and Bartelsman et al. (2008). We find, indeed, that sectors facing lower tariffs show larger correlations between market share and productivity, indicating that trade opening increases the share of productive plants and reduces the market share of less productive plants.

The rest of the paper proceeds as follows. In Section 2, we discuss the theoretical considerations that motivate our empirical analysis. In Section 3, we describe the market reforms introduced in Colombia during the 1990s. In Section 4, we present the data from the Annual Manufacturing Survey. In Section 5, we show our results on the impact of the profit margin components, and the interaction of these market fundamentals with trade reforms on exit probabilities. In Section 6, we present the implications of traderelated exits for average productivity and explore alternative channels through which tariff reductions may have affected productivity. We conclude in Section 7.

\section{Theoretical Considerations}

According to selection models of industry dynamics (e.g., Jovanovic (1982), Hopenhayn (1992), Ericson and Pakes (1995)) producers should continue operations if the discounted value of future profits exceeds the opportunity cost of remaining in operation. At the same time, recent models (e.g., Melitz (2003), Melitz and Ottaviano (2008), and Foster et al. (2008)) emphasize that many market fundamentals influence variation in profitability across producers. In this literature, producers with market power make decisions on outputs, inputs, and output prices, given productivity shocks, demand shocks, demand elasticity and input price shocks drawn by the producer from a joint distribution. These models also assume that firms face frictions in the market through entry barriers. Typically, producers are assumed not to know their market fundamentals prior to entry, pay an entry fee and obtain their first draw of their market fundamentals from a joint distribution. The market fundamentals are assumed to evolve stochastically over time and consistent with the recent empirical literature are assumed to be highly persistent processes. Given fixed costs of operating each period, the producer makes a decision on whether or not to stay or exit at each point in time. As derived in the recent literature, the canonical exit decision can be modeled as being given by: ${ }^{6}$

\footnotetext{
${ }^{6}$ See, e.g., Melitz and Ottaviano (2008) and Foster et al. (2008) for models that yield exit specifications with this full list of market fundamentals (or plant profit-margin components).
} 


$$
e_{j t}=\left\{\begin{array}{l}
1 \text { if } P D V\left\{\pi\left(T F P_{j t}, P_{I j t}, D_{j t}, \varepsilon_{j t}\right)-C_{j t}\right\}<0 \\
0 \text { if } P D V\left\{\pi\left(T F P_{j t}, P_{I j t}, D_{j t}, \varepsilon_{j t}\right)-C_{j t}\right\} \geq 0
\end{array}\right.
$$

That is, plant $j$ exits if the expected present net discounted value of profits including the fixed cost of operating $C_{j t}$ is negative. ${ }^{7}$ Current and future expected profits, $\pi$, (and, in turn, their present discounted value, PDV) gross of fixed costs are a positive function of demand, $D_{j t}$ and productivity shocks, $T F P_{j t}$, a positive function of the demand elasticity, $\varepsilon_{j t}$ (where the latter is negative so an increase implies an increase in the mark-up) and a decreasing function of input price shocks, $P_{I j t}$.

In what follows, we estimate this specification of market selection for Colombia. The estimates for the basic model are of interest in their own right, since Colombia is unique in having rich data with plant-level measures of each of these fundamentals, including demand shocks and demand elasticities. Our primary purpose is, however, to explore the role of market reforms and, in particular, trade liberalization on the market selection process.

Theory suggests that trade liberalization enhances the mechanism that drives low productivity and other under-performing plants out of the market. For example, Melitz (2003) develops a monopolistic competition model where trade liberalization impacts market selection through equilibrium wages. As the economy liberalizes, the more productive plants expand by increasing exports and this drives up the equilibrium wage. With a higher wage, only incumbents with productivity above a larger threshold survive. At the same time, Bernard et al. (2003) introduce stochastic plant productivity in a perfect competition Ricardian model where producers from the same country compete to be the sole national supplier to specific destinations. Lower trade barriers bump out low-productivity plants due to import competition, while high productivity plants grow into export markets. As labor shifts from low-productivity exiting plants to highproductivity expanding plants, there is a rise in aggregate productivity. ${ }^{8}$

\footnotetext{
${ }^{7}$ The fixed cost of operating $C_{j t}$ should be defined as being net of the option value for the plant of waiting to exit. This option value arises due to the irreversibility stemming from sunk entry costs.

${ }^{8}$ Our empirical analysis is closer to Bernard et al. (2003), as we focus on the effects of trade reform on market selection for a given set of fundamentals. By contrast, Melitz (2003) and Melitz and Ottaviano (2008) emphasize how exit will be impacted by trade through changes in fundamentals (i.e., wages and mark-ups, respectively). While these channels are likely important, studying the impact of trade on wages empirically requires richer wage data than we have from the Monthly Manufacturing Survey. For instance, the studies by Goldberg and Pavcnik (2005) and Attanasio et al. (2004) highlight the complex mechanisms through which trade may affect average wages and the distribution of wages using
} 
Another channel suggested by the recent literature on misallocation and productivity (e.g., Banerjee and Duflo (2005), Hsieh and Klenow (2009), Restuccia and Rogerson (2008) and Bartelsman et al. (2008)) is the increased relative importance of market fundamentals for exit when trade is liberalized. In these models, distortions to markets include an idiosyncratic component. In our context, trade barriers potentially yield idiosyncratic distortions as they may vary across sectors yielding more favorable treatment for some firms and less favorable treatment of other firms. A key insight from this class of models is that, in addition to the profit-margin components discussed above, these idiosyncratic distortions impact profitability and, in turn, market selection. Thus, in the presence of idiosyncratic distortions, a plant's survival becomes less related to its favorable profit-margin fundamentals, and more to regulations. For instance, protections (including trade protections) to specific sectors may allow firms in these sectors to survive even with relatively low productivity. On the other hand, when these protections are eliminated, firms will only be able to survive if they have relatively high productivity.

Given the possible mechanisms through which trade liberalization can impact market selection, our empirical strategy is based on an enhanced model of exit which includes idiosyncratic market distortions:

$$
e_{j t}=\left\{\begin{array}{l}
1 \text { if } P D V\left\{\pi\left(T F P_{j t}, P_{I j t}, D_{j t}, \varepsilon_{j t}, \tau_{j t}\right)-C_{j t}\right\}<0 \\
0 \text { if } P D V\left\{\pi\left(T F P_{j t}, P_{I j t}, D_{j t}, \varepsilon_{j t}, \tau_{j t}\right)-C_{j t}\right\} \geq 0
\end{array}\right.
$$

where $\tau_{j t}$ represents market distortions for plant $j$ including those from trade barriers. While we are not able to measure the full set of market distortions impacting any given plant, we have one good measure of distortions, namely tariffs. A key working hypothesis of our empirical analysis is that the plants in sectors with the largest decreases in tariffs are, holding other things equal (e.g., including other reforms), more likely to have seen a larger reduction in their market distortions. As noted above, a key insight from the recent literature is that the presence of idiosyncratic distortions across plants reduces the marginal effect of fundamentals on the probability of exit. ${ }^{9}$ This insight helps guide and interpret our empirical specification of the market selection models presented below. Our core identifying assumption is that sectors with greater tariff reductions

household data for Colombia. Exploring the impact of trade liberalization via changes in mark-ups would require a careful and detailed study of mark-ups similar to the studies of trade on wages by Goldberg and Pacvnik (2005) and Attanasio et al. (2004). Exploring these alternative channels is an interesting area we intend to study in future work.

${ }^{9}$ The analysis in Bartelsman et al. (2008) shows that an increase in the dispersion of idiosyncratic distortions decreases the marginal effect of market fundamentals, like productivity, on plant exit. 
have had a larger reduction in market distortions and, accordingly, fundamentals should become incrementally more relevant for market selection in the sectors with greater tariff declines. As will become clear, in practice when we estimate the above specification, we include controls and estimate flexible specifications, including both direct and interaction effects, to capture the impact of trade and other reforms.

\section{Trade Reforms in Colombia}

Colombia underwent substantial changes in trade policy during the past three decades. After considerable trade liberalization in the 1970s, the administration of president Belisario Betancurt implemented a reversal towards protection during the early 1980s in response to the appreciation of the exchange rate, which had contributed to increased foreign competition. Betancurt's policies increased the average tariff level to 27 percent in 1984, but the degree of protection across industries was far from uniform. Manufacturing sectors benefited the most from increased protection as the average tariff in manufacturing rose to 50 percent. However, even within manufacturing some sectors received more protection than others. The sector with the highest protection was textiles and apparel, which had nominal tariffs of nearly 90 percent, and wood products followed with a nominal tariff of 60 percent. These two sectors also had the highest levels of protection through non-tariff barriers.

While barriers to trade were reduced in the second half of the 1980s, trade was largely liberalized in Colombia during the first half of the 1990s. Figure 1 shows average effective tariffs and the standard deviation of effective tariffs starting in $1984 .{ }^{10}$ From this initial level, the figure shows a substantial decline both in average effective tariffs and the dispersion of these tariffs in 1985. The figure then shows a gradual decrease in tariffs which started during the administration of president Virgilio Barco in the late 1980s.

In 1990, the administration of president Cesar Gaviria introduced a comprehensive reform package, which included measures to modernize the state and liberalize markets. Reforms during the 1990s occurred in the areas of trade, financial and labor markets, privatization and the tax system. ${ }^{11}$ Probably the most important of all these reforms

\footnotetext{
${ }^{10}$ The effective tariff for a given final good adjusts the nominal tariff levied to the good itself, by substracting the weighted sum of tariffs on the inputs used to produce that good, where the weights are given by the share of the input in production costs for that good (using the corresponding entry in the Input-Output table).

${ }^{11} \mathrm{~A}$ number of studies have examined the impacts of non-trade reforms on workers and firms. Kugler
} 
was the trade reform carried out at the beginning of the 1990s.

The average nominal tariff declined from 27 to about 10 percent overall, and from 50 to 13 percent in manufacturing, between 1984 and 1998. As Figure 1 shows, there was a drastic drop in average effective tariffs and in the dispersion of effective tariffs between 1990 and 1992 during the Gaviria administration. By 1992, the average effective tariff was at $26.6 \%$ compared to $62.5 \%$ in 1989 and compared to $86 \%$ in 1984 . Similarly, the dispersion of tariffs fell substantially during the early 1990s, though dispersion across industries still remained substantial as the standard deviation of tariffs remained at around 0.2 .

After Gaviria's term, Ernesto Samper won the presidential election in 1994 based on a platform which partly opposed trade liberalization and other reforms. ${ }^{12}$ While the new government did not dismantle the existing reforms at the time, it managed to stop the momentum for further liberalization. This is clear in Figure 1, which shows that the average and standard deviation of effective tariffs remain flat after 1992.

The description above makes clear that there were important changes in both the mean level and the dispersion of tariffs across sectors. An interesting aspect of the Colombian trade reforms is that at the same time that the overall level of protection was lowered, the sectoral structure of protection was also substantially altered as barriers to trade were lowered to similar levels across sectors irrespective of their initial level. The identification strategy of our analysis of the effect of market reforms on market selection exploits this cross-sectional variation in tariff reductions.

\section{Data}

Since we are interested in estimating the impact of market fundamentals on exit as trade opens, we require information on tariffs, and on plant characteristics, including: productivity, demand shocks, demand elasticities, and input prices. Also, to control for other ongoing reforms that may had coincided with the trade reforms, in some specifications we require a measure of other regulations. In this section, we provide a

(1999, 2005) studies the impact of the 1991 labor market reforms, Kugler and Kugler (2009) studies the impact of the 1993 payroll tax reform; Kugler (2006) studies the impact of the 1992 FDI reform, and Eslava et al. (2009) study the impact of the 1991 labor and capital market reforms.

${ }^{12}$ Note that the Colombian electoral system at the time ruled out re-election after one term in office, which may help explain the depth of the structural reforms in Colombia in the absence of an economic crisis. 
description of the data, and we then explain the measurement of physical productivity and demand shocks.

\subsection{Data Description}

We use data from the Colombian Annual Manufacturing Survey (AMS), an unbalanced panel that registers information on all manufacturing establishments with 10 or more employees. Establishments with less than 10 employees but with a nominal value of production over a certain level are also included. ${ }^{13}$ Given that these requirements are satisfied, a plant is then included in our sample in a given year if it reports positive production for that year. We have data covering the 1982-1998 period, at an annual frequency. The AMS records include information on the value of production, number of employees, value of materials used, physical units of energy demanded, value of the stock of capital and purchases of capital, as well as the quantities of each product it manufactures and of each material it uses.

\subsubsection{Plant-level Prices of Inputs and Output}

We start by constructing output and material price indices for each establishment, using the information on individual products and materials for each plant. To create a plantlevel index of material prices, we first calculate weighted averages of the price changes of all individual materials used by the plant. ${ }^{14}$ The weight assigned to each input corresponds to the average share (over the whole period) of that input in the total value of materials used by the plant. ${ }^{15}$ Plant-level price indices are then generated recursively from these plant-level price changes, where we set 1982 as the base year. Given the recursive method used to construct the price indices and the fact that we do not have plant-level information for material prices for the years before plants enter the sample,

\footnotetext{
${ }^{13}$ For instance, for 1998 the value limit was set at U $\$ 35,000$.

${ }^{14}$ Since some large outliers appear, we trim the $1 \%$ percent tails of the distribution of plant-level price changes. In addition, given that the inflation rate in Colombia has hovered around $18 \%$ during the period, we choose to drop observations that show reductions of prices beyond $50 \%$ in absolute value or increases in prices beyond $200 \%$.

${ }^{15}$ An alternative specification would be to use a Divisia index approach letting the share in any given year be the average of the share in the current and prior year. We have used this alternative approach and obtain similar results. However, we find some anomalous large and transitory fluctuations in the shares suggesting problems with measurement error. Given these concerns, we use a more conservative approach using the average over the entire period.
} 
we replace missing values with the average material price in the plant's sector, location, and year. ${ }^{16}$ A similar method is used to construct output price indices.

We use plant-level output prices to construct physical quantities of output, which are measured as the nominal output deflated by the plant-level price index. Similarly, we construct physical quantities of materials used as the nominal value of these materials deflated by the plant-level materials price index. Physical quantities of energy usage are directly reported at the plant-level.

\subsubsection{Capital Stock}

We construct a series of the capital stock for each plant, $j$, following the perpetual inventory method. Gross investment is generated from the information on fixed assets reported by each plant, using the expression:

$$
I_{j t}=K_{j t}^{N F}-K_{j t}^{N I}-d_{j t}-\pi_{j t}^{A},
$$

where $K_{j t}^{N F}$ is the reported final value of fixed assets by plant $j$ at the end of year $t$, $K_{j t}^{N I}$ is the reported initial value of fixed assets reported by plant $j$ at the start of year $t, d_{j t}$ is the depreciation reported by plant $j$ at the end of year $t$, and $\pi_{j t}^{A}$ is the reported inflation adjustment to fixed asset value by plant $j$ at the end of year $t$ (only relevant since 1995, the first year in which plants were required by law to consider this component in their calculations of end-of-year fixed assets). We deflate gross investment using a deflator for capital formation from National Accounts' Input-Output matrices (or the equivalent "output utilization matrices" since 1994); the deflator varies in general at the 2-digit sector level, and for a few sectors at a higher level of disaggregation. Denote this deflator as $D_{S(j) t}$ where $S(j)$ is the sector to which plant $j$ belongs. The plant capital stock is, thus, constructed recursively following:

$$
K_{j t}=\left(1-\delta_{S(j)}\right) K_{j t-1}+\frac{I_{j t}}{D_{S(j) t}},
$$

where $\delta_{S(j)}$ is the depreciation rate for the 3-digit sector to which plant $j$ belongs calculated by Pombo (1999). We initialize the capital stock for each plant using the nominal capital stock first ever recorded (at the beginning of year), $K_{j t_{0}}^{N I}$, deflated by the average capital deflator for the current and previous years, $D_{S(j) t_{0}}$ and $D_{S(j) t_{0}-1}$ :

\footnotetext{
${ }^{16}$ When the information is not available by location, we impute the national average in the sector for that year. This imputation assumes that the plant that is about to enter would have had a similar product mix as existing plants in the same sector-location-year.
} 


$$
K_{j t_{0}}=\frac{K_{j t_{0}}^{N I}}{\frac{1}{2}\left(D_{S(j) t_{0}}+D_{S(j) t_{0}-1}\right)} .
$$

\subsubsection{Employment}

The level of employment or the number of workers is reported directly by each establishment. Since hours per worker are not reported in the AMS, we construct a measure of labor usage, by using information on average wages at the 3-digit sector level from the Monthly Manufacturing Survey. ${ }^{17}$ Our measure of hours per worker in sector $S(j)$ to which plant $j$ belongs is:

$$
H_{S(j) t}=\frac{\operatorname{earnings}_{S(j) t}}{w_{S(j) t}},
$$

where $w_{S(j) t}$ is the measure of sectoral hourly wages at the 3 -digit level, and earning $s_{S(j) t}$ is a measure of earnings per worker constructed from our data as

$$
\text { earnings }_{S(j) t}=\frac{\sum_{j \in S} \text { payroll }_{j t}}{\sum_{j \in S} L_{j t}} .
$$

\subsubsection{Descriptive Statistics of Plant-level variables}

Table 1 presents descriptive statistics of the quantity and price variables just described. ${ }^{18}$ The price and quantity variables are expressed in logs. We restrict our sample to plants in three-digit sectors with more than 25 establishments in the average year, since we make use of within-sector variation in our analysis below. In the next section, we use the variables summarized in Table 1 to estimate the production function and inversedemand equation.

Table 1 also shows entry and exit rates. A plant is classified as entering in $t$ if it exists in our sample in year $t$ but not in $t-1$. Similarly, the plant exits in $t$ if it exists

\footnotetext{
${ }^{17}$ Data on sector wages are reported separately for production and non-production workers. We use a weighted average of the wages of those two categories, where the weights are the shares of each type of worker in total sector employment. We deflate the nominal wages using the CPI obtained from the National Department of Statistics.

${ }^{18}$ The descriptive statistics capture both within industry as well as between industry variation. In the empirical analysis, we always control for industry effects, so we focus our attention on within industry variation (across plants and across time) in our estimation. Interestingly, we have generated a version of Table 1 that removes industry effects and find very similar patterns, suggesting that much of the between plant variation in outputs, inputs and prices reflects within industry variation.
} 
in the sample in $t$ but not in $t+1$. Note that Table 1 reports entry and exit rates of $7 \%$ and $9 \%$ respectively, somewhat lower than those reported for developed countries (Davis et al. (1996)). These lower entry and exit rates for Colombia are consistent with the perception that developing economies are subject to greater rigidities than more developed countries (see Tybout (2000) for a discussion of this issue).

\subsubsection{Tariffs and Reform data}

Our data on effective tariffs come from the National Planning Department. Effective tariffs are available at the product level for each year, using a classification system (and therefore product identifiers) that were created for the Andean Community. Since the tariffs' database also assigns each of these products a four-digit sector ISIC code, we can construct effective tariffs at the four-digit level by averaging effective tariffs across products in a given sector. The only other study of the impact of trade liberalization on productivity with a similar level of disaggregation of tariffs is that by Trefler (2004). Having effective tariffs at this high level of dissagregation allows us to still control for sector effects in our estimation, using 2-digit sector dummies which may capture other factors affecting exits. On the other hand, the fact that we use sector-level rather than plant-level tariffs reduces concerns about tariffs being influenced by individual firms. In addition, we limit our analysis to 3 -digit sectors with more than 25 establishments in the average year. Moreover, as a robustness check, we drop the most concentrated sectors (based on a Herfindahl Index) from our analysis and find no differences with our results based on the overall sample.

We also use an index of reforms other than trade in some of our specifications. We construct this index from the institutions index produced by Lora (2001). Lora generates indices of market reform in each of five areas: labor regulation, financial sector regulation, trade openness, privatization and taxation. He then averaged those individual indices to construct an index of overall reform. The indices for individual areas of regulation fall in a 0-1 scale, where 0 (1) corresponds to the most (least) rigid institutions in Latin America over the period for each of the five categories that compose the aggregate index. We modify Lora's index in two ways. First, we exclude trade reform from the calculation of the overall index, since we look at trade institutions directly through tariffs. Second, we use a different 0-1 scale, where the index in each category is calculated relative to the minimum and maximum level of reform in Colombia during the period, rather than relative to the minimum and maximum for Latin America. The Lora index is only available since 1985, so that the regression analysis that includes this 
index as a control is restricted to the period 1985-1998.

The evolution of the means and standard deviations of effective tariffs, as well as the index of other reforms (which only varies over time) are shown in Figure 1. As described above, both the mean and the standard deviation of effective tariffs go down significantly between 1984 and 1992, and then show little variation. Figure 1 also shows that the index of other reforms, which goes up during the 1990s when market reforms are implemented, increased at the same time that tariffs were being reduced. This highlights the importance of controlling for other reforms in our estimation.

\subsection{Estimation of Productivity and Demand Shocks}

We begin by estimating production and demand functions at the plant level, to obtain measures of TFP, demand shifters and the elasticity of demand. Following Eslava et al. (2004), our TFP estimates are constructed using factor elasticities estimated using downstream demand to instrument inputs, while our demand estimation uses TFP as an instrument.

\subsubsection{Total Factor Productivity}

We estimate total factor productivity for plant $j$ in year $t$ as the residual from a production function:

$$
Y_{j t}=K_{j t}^{\alpha}\left(L_{j t} H_{j t}\right)^{\beta} E_{j t}^{\gamma} M_{j t}^{\phi} V_{j t}
$$

where, $Y_{j t}$ is output, $K_{j t}$ is capital, $L_{j t}$ is total employment, $H_{j t}$ are hours per worker, $E_{j t}$ is energy consumption, $M_{j t}$ are materials, and $V_{j t}$ is a productivity shock.

Our total factor productivity measure is estimated as:

$$
T F P_{j t}=\log Y_{j t}-\widehat{\alpha} \log K_{j t}-\widehat{\beta}\left(\log L_{j t}+\log H_{j t}\right)-\widehat{\gamma} \log E_{j t}-\widehat{\phi} \log M_{j t} .
$$

where $\widehat{\alpha}, \widehat{\beta}, \widehat{\gamma}$, and $\widehat{\phi}$ are the estimated factor elasticities for capital, labor hours, energy, and materials. Since productivity shocks are likely to be correlated with inputs, OLS estimates of factor elasticities are likely to be biased. We thus rely on IV estimates, where the instruments are demand shifters, input prices, and government spending which are likely correlated with input but uncorrelated with productivity shocks. A more detailed description of this estimation and its results can be found in Eslava et al. (2004). ${ }^{19}$

\footnotetext{
${ }^{19}$ Although the sample differs slightly because we drop observations from sectors with few establishments, the estimated factor elasticities we report here are the same as those in Eslava et al. (2004) up to the second decimal place.
} 
Table 2 presents summary statistics for our TFP measure estimated with instrumental variables (labeled TFP in this Table), and compares it to alternative measures of productivity. All statistics are computed at the three-digit level. We compare our IV TFP measure with a TFP measure estimated using cost shares at the 3-digit level as factor elasticities (TFPC) and with a TFP measure estimated using factor elasticities from an OLS estimation of the production function (TFPO). Our TFP measure is highly correlated with both of these alternatives, with correlation coefficients above 0.85 . Thus, in spite of the differences in estimated factor elasticities obtained using various methods, we find that the TFP distribution across plants is similar. ${ }^{20}$ The similarity between our TFP measure and the cost shares TFP measure suggests that allowing factor elasticities to vary across sectors is not crucial for TFP estimation in our data. In the rest of the paper, we rely on TFP estimates based on our IV estimation.

Table 2 also shows other interesting patterns that we exploit in our analysis in the following sections. First, the table shows considerable dispersion in plant-level prices and TFP within sectors, which is consistent with the association between price and productivity dispersion and frictions pointed out in recent literature. In addition, price dispersion is consistent with the common assumption of product differentiation in the recent literature.

Second, Table 2 shows that TFP (measured either using our preferred measure in row 1 of Table 2 or TFPC which uses the cost share factor elasticities) is inversely correlated with plant-level prices. This is consistent with more productive plants or industries having lower marginal costs and setting lower prices when faced with downward sloping demand curves. ${ }^{21}$ We exploit this inverse relationship to estimate demand elasticities

\footnotetext{
${ }^{20}$ The finding that the distribution of plant-level TFP is robust to alternative estimation methods is analogous to related findings by van Biesebroeck (2006). There are alternative ways to estimate factor elasticities in the literature such as Olley and Pakes (1996) and Blundell and Bond (1999). The Olley and Pakes method (and related methods in the literature) uses a proxy approach to deal with endogenous factors of production. However, as discussed in Foster et al. (2008), these proxy methods are less suitable for specifications with both demand shocks and productivity shocks (there is an omitted variable problem in the proxy inversion). Nonetheless, we generated TFP measures using proxy methods and also find that the resulting TFP measures are highly correlated with our TFP measure estimated using instrumental variables.

${ }^{21}$ One possible concern in interpreting this inverse correlation between TFP and prices is division bias. TFP is physical output per unit input but physical output is based on the ratio of nominal output to plant-level prices. If there is measurement error in prices this can yield an inverse correlation in TFP and prices. To explore the relevance of this concern, we also have estimated the correlation between lagged TFP and current prices. If measurement error in plant-level prices is white noise then this
} 
and demand shocks in the next section. This finding is also useful to provide insights as to the underlying sources and interpretations of price variation. As noted, price dispersion is consistent with product differentiation. This product differentiation may reflect horizontal or vertical differentiation. As such, some of the price variation may reflect product quality variation. While it is obviously of interest to ultimately sort out the nature of this product differentiation, this is not the focus of the current analysis. However, we note that the inverse correlation between TFP and prices is consistent with more efficient producers moving along downward sloping demand curves. ${ }^{22}$ For our purposes, then, if plant-level prices in part reflect variation in product quality (as well as potentially other sources of idiosyncratic demand shocks), our underlying assumption is that such variation in product quality is not correlated with TFP so that TFP serves as a good instrument for the output price in the demand function. ${ }^{23}$

Table 2 also illustrates the importance of being able to measure plant-level prices and physical efficiency. TFP2 is a measure of "revenue" productivity, similar to that used more frequently in the literature, given the absence of plant-level prices. Similar to the other measures of productivity we have reported, it is calculated using equation (1), but where $Y_{j t}$ is plant-level output divided by sectoral-level price indices and $M_{j t}$ is expenditures on materials divided by sectoral-level materials price indices. Although TFP and TFP2 are positively related, the correlation coefficient is only 0.68 , significantly below the correlation of TFP with both TFPC and TFPO, where the latter all use plant level prices. Moreover, TFP2 is essentially uncorrelated with plant-level prices. Indeed, the relation between prices and productivity, which we exploit in our data to identify demand elasticities and shocks, disappears when sector-level deflators are used. The reason for this is straightforward: variation in TFP2 directly reflects the variation in prices, and the resulting positive correlation with plant-level prices offsets the negative correlation between prices and physical productivity (TFP).

\subsubsection{Demand Estimation}

While productivity is likely to be one of the crucial components of profitability, as discussed in Section 2, other components are also probably important determinants of

eliminates the division bias. The average within sector correlation of lagged TFP and current prices is -0.59 which is similar in magnitude to the -0.65 correlation between TFP and prices in Table 2 .

${ }^{22}$ We find that this inverse correlation holds for all 3-digit sectors.

${ }^{23}$ If productivity shocks and product quality were positively related, we would be more likely to observe a positive correlation between TFP and prices. 
profitability and survival. For example, even if plants are highly productive, they may be forced to exit the market if faced with large negative idiosyncratic demand shocks. Another important determinant of exits is likely to be the degree of market power of a producer, which empirically can be captured by the mark-up or the inverse of the demand elasticity. In this section, we describe how we estimate both the demand shocks as well as demand elasticities.

Our demand shock measure is estimated as the residual from estimating a demand equation, which in its simplest form may be written (in logs) as:

$$
\log Y_{j t}=\varepsilon_{j} \log P_{j t}+\log D_{j t} .
$$

In this case, the demand shock is estimated using the following expression:

$$
d_{j t}=\log \widehat{D_{j t}}=\log Y_{j t}+\widehat{\varepsilon}_{j} \log P_{j t},
$$

where $d_{j t}$ is the demand shock faced by firm $j$ at time $t$ and $\widehat{\varepsilon}_{j}$ is the estimated elasticity of demand, which may potentially vary across plants or sectors and which is strictly negative in the presence of a downward sloping demand.

Using OLS to estimate the demand function is likely to generate an upwardly biased estimate of demand elasticities because demand shocks are positively correlated to both output and prices, so that $\widehat{\varepsilon}$ will be smaller in absolute value than the true $\varepsilon$. To eliminate the upward bias in our estimates of demand elasticities, we use TFP as an instrument for $P_{j t}$ since TFP is negatively correlated with prices but unlikely to be correlated with demand shocks (Eslava et al. (2004)). ${ }^{24}$ Also, to avoid potential problems from measurement error and associated division bias, we use lagged TFP as the instrument.

Columns (1) and (2) of Table 3 report the OLS and IV results from the simple demand equation. For consistency with other estimations reported below, the estimation is done pooling establishments from all sectors and controlling for sector effects at the 2-digit

\footnotetext{
${ }^{24}$ In the macro literature on TFP there is considerable attention paid to measured cyclical fluctuations in TFP being associated with unmeasured changes in factor utilization (see, e.g., Basu and Fernald (2000)). As such, at the aggregate level, the assumption of measured TFP and aggregate demand shocks being uncorrelated may be problematic. However, we are mostly exploiting cross sectional variation in plant-level TFP with the variance of idiosyncratic shocks an order of magnitude larger than any aggregate shocks. Moreover, the idiosyncratic TFP and demand shocks we estimate are highly persistent suggesting that issues about cyclical factor utilization are dwarfed by the highly persistent idiosyncratic shocks (thus, inducing relatively little idiosyncratic variation in unmeasured factor utilization). Also, to the extent that energy usage proxies for capacity utilization, we would be taking the utilization factor out of our TFP measure.
} 
level. We control for sector effects to control for unobserved sectoral heterogeneity and we estimate robust standard errors. ${ }^{25}$ OLS results presented in Column (1) yield an estimated elasticity of -0.87. Meanwhile, IV results in Column (2), which use (lagged) TFP as an instrument, show a much higher average elasticity (in absolute value) of -2.12.

We also estimate a different demand specification, in which we let the demand elasticity vary over time and by a plant's location. To do this, we include the density of roads in the state in which the plant is located both as a control and as an interaction variable in the demand specification. The idea behind including density of roads is that this is a good proxy for access to markets, so that we should expect demand to increase as the density of roads increases and also competition to increase as access to markets improves. In this case, the demand equation may be written as,

$\log Y_{j t}=\lambda_{0}+\lambda_{1} \log P_{j t}+\lambda_{2}$ Density $_{R(j) t}+\lambda_{3}$ Density $_{R(j) t} \times \log P_{j t}+\psi_{S(j)}+\xi_{R(j)}+\log D_{j t}$, where Density D $_{R(j) t}$ is measured in kilometers of paved roads per square kilometer of total area of the state $R(j)$ in which plant $j$ is located, $\psi_{S(j)}$ are 2-digit sector effects and $\xi_{R(j)}$ are region (state) effects. ${ }^{26}$ The latter control for unobserved sectoral and regional heterogeneity. In particular, region fixed effects are added to control for unobserved factors at the region level that may drive demand as well as be correlated with road density. As in the previous case, we estimate robust standard errors. We also include national level GDP growth as an additional control, to make sure that the variation of roads over time is not simply reflecting other aggregate effects. In this case, the demand shock is again estimated as the components of demand after abstracting from the impact of price, while the demand elasticity may be written as:

$$
\widehat{\varepsilon}_{R(j) t}=\lambda_{1}+\lambda_{3} \text { Density }_{R(j) t} .
$$

Column (3) of Table 3 reports results for this specification. As expected, we find that increased road density increases the demand for output. Also, increased road density

\footnotetext{
${ }^{25}$ Wooldridge (2002) notes that in models with unobserved heterogeneity at the group level assumptions need to be made about the form of this heterogeneity. One could assume that the unobserved heterogeneity is not correlated with the RHS variables and then use random effect estimators and/or clustered standard error corrections as appropriate. He notes that permitting fixed effects that are potentially correlated with RHS variables is more robust than these alternatives but also notes that robust standard error estimators are required. It is this latter approach that we use throughout this analysis.

${ }^{26}$ The density measure varies across states and over different decades (1980s and 1990s). The data were provided by CEDE.
} 
increases the demand elasticity (in absolute terms), consistent with the idea that greater competition due to greater access to markets makes demand more responsive to changes in prices. $^{27}$

In what follows, we use the estimates of demand shocks and elasticities from Table 3 in our analysis of the impact of market fundamentals on plant exit. As will become clear, we explore analyses using the estimates from both Columns (2) and (3) of Table 3.

\section{Effects of Market Fundamentals and Tariffs on Plant Exit}

\subsection{The Role of Market Fundamentals for Selection}

As discussed in Section 2, the characterization of the exit decision implies that the plant ceases operations if its net present discounted value of profits (inclusive of fixed costs of operating) is negative. Assuming that the fixed cost, $u_{j t}$, is drawn from a normal distribution, we can in practice estimate a plant's probability of exit using a probit model, where we specify the probability of exit between $t$ and $t+1$ as a function of measures of market fundamentals in period $t-1:^{28}$

$\operatorname{Pr}\left(e_{j S(j) R(j) t}\right)=\operatorname{Pr}\left(\kappa_{S}+\theta_{G} G D P_{t}+\theta_{1} T F P_{j t-1}+P_{I j t-1}^{\prime} \Theta_{2}+\theta_{3} D_{j t-1}+\theta_{4} \varepsilon_{R(j) t-1} \leq u_{j t}\right)$,

where $e_{j s(j) R(j) t}$ takes the value of 1 if the plant $j$ in sector $S(j)$ and region $R(j)$ exits between periods $t$ and $t+1 ; \kappa_{S}$ are 2-digit industry effects; $G D P_{t}$ is the growth of

\footnotetext{
${ }^{27}$ It would be interesting to explore demand structures that permit richer variation in plant-level mark-ups. Another idea suggested to us by Chad Syverson would be to use our data to compute plantspecific mark-ups directly. That is, use our plant-specific cost data to estimate marginal costs and then compute mark-ups at the plant-level. Investigating the properties of such mark-ups including how they vary across different types of plants and how they may have changed in response to market reforms is an interesting empirical agenda that we plan to pursue in future related work.

${ }^{28}$ To justify a probit we require that there be some unobserved heterogeneity beyond the fundamentals that we measure to account for the variation in the data on plant exit. One obvious candidate is variation in the fixed cost of operating each period. Alternatively, there could be some other component of operating profits that is unobserved but uncorrelated with the fundamentals that we do observe. For ease of exposition, we refer to this stochastic unobserved heterogeneity as a stochastic fixed cost in the text.
} 
aggregate gross domestic product in year $t$; $T F P_{j t-1}$ measures productivity in period $t-1, P_{I j t-1}$ is a vector of energy and materials prices in period $t-1 ; D_{j t-1}$ is a demand shifter in period $t-1 ; \varepsilon_{R(j) t-1}$ is the price elasticity of demand for plant $j$ in region $R(j)$ in period $t-1$, and $u_{j t}$ is an i.i.d. normally distributed error term. In what follows, we consider alternative specifications of this basic equation using the alternative measures of market fundamentals that we have developed in the analysis above. ${ }^{29}$

Table 4 reports summary statistics for the determinants of exit included in equation (4) (except for input prices which are reported in Table 1), as well as for effective tariffs and indices of other reforms, which will be included in an expanded specification. The sample has been limited to the observations that enter those estimations. Since the index of other reforms is only available since 1985, our estimation period for the exit equations is $1985-1998$.

Table 5 reports the marginal effects obtained from estimating the baseline specification in equation (4), as well as specifications with additional more controls in each subsequent column. In all the specifications in Table 5, we include 2-digit sector fixed effects to control for unobserved sectoral heterogeneity and we estimate robust standard errors. Marginal effects are calculated setting all right-hand-side variables at their mean levels. Column (1) reports the effect of productivity and input prices on plant exit when 2-digit sector fixed effects and aggregate GDP growth are included, but idiosyncratic demand effects are left out. As expected, higher lagged productivity is negatively related to the probability of exit, while higher lagged energy and material prices are positively related with the probability of leaving the market. In particular, a one standard deviation increase in TFP from its mean level yields a 1.1 percentage point decrease in the probability of exit, and one standard deviation increase in energy and material prices yield respective increases of 0.35 and 0.6 percentage points in the probability of exit. ${ }^{30}$ Since the average exit probability is $9 \%$, these effects, especially the one associated with

\footnotetext{
${ }^{29}$ We use fundamentals dated at time $t-1$ to predict exit from $t$ to $t+1$ given possible incomplete measurement and endogeneity issues in period $t$ (the period just prior to exit). Our data are calendar year data but there may be mid-year exits which may yield measurement error in fundamentals for part year plants. Moreover, if the process of exit itself as the plant shuts down impacts fundamentals there is a problem of reverse causality. The use of period $t-1$ information mitigates both of these concerns.

${ }^{30}$ Note that because our exit model is not linear and because one standard deviation changes in the fundamentals are not marginal changes, these effects cannot be simply obtained by multiplying the change in the fundamental by its marginal effect. We obtain them by evaluating the probability of exit when one fundamental is one standard deviation away from its mean and the others are at their means, and calculating the difference between that probability and the probability of exit when all regressors are at their means.
} 
TFP, reflect large percentage changes in the probability of exit.

Columns (2) to (4) of Table 5 report results including idiosyncratic demand effects. Column (2) includes the output price as a rough control for demand, while Columns (3) and (4) include our measures of demand shifts and elasticities. The results in Column (3) use the demand shocks from Column (2) of Table 3 - this is the relevant specification when we do not permit elasticities to vary across plants. For this specification, we find that a one standard deviation increase in TFP and demand yields respective reductions of 1.2 and 3.1 percentage points in the probability of exit, while a one standard deviation increase in energy and material prices yield a 0.4 and 0.8 percentage points increase, respectively, in the probability of exit. ${ }^{31}$

When we permit elastiticies to vary across plants consistent with Column (3) of Table 3 (where elasticities vary with road density), a one standard deviation demand shock yields a 3 percentage points reduction in the probability of exit. A one standard deviation increase in the price elasticity reduces the probability of exit by 0.28 percentage points. Since the price elasticity of demand is strictly negative, a larger demand elasticity (i.e., closer to zero) is associated with more inelastic demand, so that more market power reduces exit. The effects of TFP and input prices are very similar in Columns (3) and (4).

To help put the results in this section into perspective, we note that many empirical papers on market selection include controls for plant size and age and find that younger and smaller plants are more likely to exit. In our view, these variables are typically included to proxy for unobserved market fundamentals. In our case, we have a very rich set of fundamentals that are motivated by the theory. For example, our demand shock measure captures variation in scale not driven by variation in productivity, and thus we do not include size as a control. Put differently, our scale measure emerges directly from the theory while typical measures of size (e.g., total number of employees) are endogenous and functions of the market fundamentals that we have measured. We note, however, that a case could be made for inclusion of an endogenous state variable related to size - namely the capital stock. As a robustness check, we estimated similar specifications to those in Table 5 but also including the lagged capital stock and found that these results are robust to inclusion of this variable. Moreover, we found that

\footnotetext{
${ }^{31}$ We report results with the output price included directly into the exit equation in Column (2) to show that the effect of the demand shock is similar whether we disaggregate the mark-up and idiosyncratic demand or whether we take a rougher measure. To the extent that there are any concerns about being able to separate the demand shock and elasticities, it is reassuring to note that the results in Column (2) and those in Columns (3) and (4) are similar.
} 
plants with a bigger capital stock are associated with a lower probability of exit. We do not include capital either in the baseline specification when we examine the interaction with tariffs, to keep the focus on market fundamentals. However, in unreported results available upon request, we find that subsequent analysis to also be robust to the inclusion of capital. ${ }^{32}$

Finally, we note that while we have a very rich set of fundamentals that capture a great deal of variation across plants, it is possible that some unobserved heterogeneity in the fundamentals underlying current and future expected profitability remains. This might mean, for example, that estimated effects of the observed cost variables are also capturing the effects of unobserved cost factors that are correlated with the observed measures. For many of the purposes of this paper, this is not a critical concern since we would still interpret our results as providing insights into the role of market fundamentals for market selection. However, as exploratory analysis and as a robustness check we estimated the specifications in Table 5 as linear probability models with establishment fixed effects. ${ }^{33}$ Interestingly, we find that our results are robust to this specification. In fact, we find that the marginal effects of TFP, energy prices, demand and market power become larger when plant effects are included. We found this robustness check reassuring but regard our baseline specification as being more closely tied to the theory where plants receive draws from the distribution of market fundamentals with plant-level persistence in these draws.

\subsection{The Interaction of Tariffs and Market Fundamentals for Selection}

In order to assess the impact of trade reform on market selection, we add the sectoral tariffs as well as interactions of these with market fundamentals to the baseline probit specification. We also include an index for other contemporaneous reforms which occurred at the same time as the trade reform. This index summarizes the degree of flexibility in the areas of labor and capital market regulations as well as the extent of

\footnotetext{
${ }^{32}$ As an additional unrelated robustness check, we also explored whether our results in Table 5 are robust to the exclusion of the plant-year observations in 1991-92. Given changes in processing of the longitudinal identifiers in the plant-level data in those years, these are years for which we had to devote considerable effort to develop consistent longitudinal identifiers. We found that the results are robust to the exclusion of these years.

${ }^{33}$ With this large a sample, estimation of linear probability models yields similar results to probit models, although with potential problems of interpretation.
} 
market orientation in terms of the tax system and privatization. Since the 1990 s were characterized by the introduction of widespread reforms in all of these areas, it is important to control for other reforms to make sure that tariffs are not picking up these additional institutional changes. The following equation is estimated:

$$
\begin{aligned}
\operatorname{Pr}\left(e_{j S(j) R(j) t}\right)= & \operatorname{Pr}\left(\kappa_{S}+\theta_{G} G D P_{t}+\theta_{1} T F P_{j t-1}+P_{I j t-1}^{\prime} \Theta_{2}+\theta_{3} D_{j t-1}+\theta_{4} \varepsilon_{R(j) t-1}\right. \\
+ & \theta_{5} \tau_{S(j) t}+\theta_{5,1} T F P_{j t-1} \times \tau_{S(j) t}+\left(P_{I j t-1} \times \tau_{S(j) t}\right)^{\prime} \Theta_{5,2} \\
& \quad+\theta_{5,3} D_{j t-1} \times \tau_{S(j) t}+\theta_{5,4} \varepsilon_{R(j) t-1} \times \tau_{S(j) t} \\
& +\theta_{6} R_{t}+\theta_{6,1} T F P_{j t-1} \times R_{t}+\left(P_{I j t-1} \times R_{t}\right)^{\prime} \Theta_{6,2} \\
& \left.\quad+\theta_{6,3} D_{j t-1} \times R_{t}+\theta_{6,4} \varepsilon_{R(j) t-1} \times R_{t} \leq u_{j t}\right)
\end{aligned}
$$

where $e_{j S(j) R(j) t}, \kappa_{S}, G D P_{t}, T F P_{j t-1}, P_{I j t-1}, D_{j t-1}$, and $\varepsilon_{R(j) t}$ are defined as in equation (4). $\tau_{S(j) t}$ is the tariff in sector $S(j)$ in year $t$, and $R_{t}$ stands for the index of reforms other than trade at time $t$. We regard this flexible specification with interactions as consistent with the canonical model of plant exit discussed in Section 2. In particular, this specification permits us to test and explore our primary hypothesis - that is, that plants in sectors with a greater reduction in tariffs will exhibit a decline in market distortions and, in turn, the marginal effect of market fundamentals on exit will increase. The interaction effects in the above specification are included to test this hypothesis. We control for GDP growth rather than time effects since much of the variability of tariffs we want to exploit, in particular the general pattern of trade liberalization, occurs over time. ${ }^{34}$ We consider alternative versions of this interacted specification using the alternative measures of market fundamentals developed in prior sections.

Given the presence of interaction terms, note that, for example, the marginal effect of productivity in model (5) is now given by:

$$
\frac{\partial \operatorname{Pr}\left(e_{j S(j) R(j) t}\right)}{\partial T F P_{j, t-1}}=F^{\prime}\left(X_{j t}^{\prime} \Theta\right)\left[\theta_{1}+\theta_{5,1} \tau_{S(j) t}+\theta_{6,1} R_{t}\right]
$$

where $F^{\prime}$ is the marginal density for the normal distribution, and $X_{j t}^{\prime} \Theta$ summarizes all covariates and coefficients in (5). A similar expression applies for the marginal effects of

\footnotetext{
${ }^{34}$ As a robustness check, we also estimated similar regressions where GDP growth is replaced with time effects. As in our baseline case, we still find enhanced market selection after trade liberalization, as productivity becomes a more important determinant of exit at lower levels of tariffs. The fact that this effect is present when including time dummies probably indicates that the cross-sectional variability of tariffs is what matters for market selection. The other effects of tariffs on the determinants of exit show similar qualitative effects when including time dummies, although the changes of these effects induced by the trade reform are estimated less precisely.
} 
other fundamentals.

Table 6 reports results of specifications that include interaction terms as in equation (5). Table 6 presents two alternative versions of the estimation. The first three columns are based on the fundamentals that emerge when demand elasticities do not vary across plants while the second three columns use the fundamentals that emerge when demand elasticities vary by road density. Each row reports the marginal effect for the corresponding variable, following the example of equation (6). Marginal effects are calculated at the mean value for all variables, except for tariffs, which are allowed to vary across columns. In Columns (1) and (4) tariffs are set at 60\%, and in Columns (2) and (5) they are set at 20\%. Since the mean value of tariffs is $56 \%$, the effects reported in Columns (1) and (4) are close to what is obtained by setting tariffs at their mean values. These marginal effects are based on the estimation of equation (5), which includes interaction of all fundamentals with both effective tariffs and the index of reforms other than trade. Columns (3) and (6) of Table 6 report the difference between the effects in Columns (1) and (2) and in Columns (4) and (5), respectively. Consequently, Columns (3) and (6) show changes in the marginal effects of each fundamental when tariffs fall from $60 \%$ to $20 \%$; in this way, we focus in a discrete change in tariffs such as the one that took place in Colombia. ${ }^{35}$

Results from Column (1) show that the effects of fundamentals are in general consistent with those estimated with the more parsimonious model reported in Table 5. The only exception is that the marginal effect of energy prices is not statistically significant. Results on the effects of a reduction in effective tariffs from $60 \%$ to $20 \%$ reported in Column (3) show that a reduction in tariffs increases the impacts of plant productivity, input prices, and demand shocks on the exit probability. In particular, the marginal effect of an increase in productivity on the probability of exit is -1.5 percentage points if tariffs are at $60 \%$, and -2.0 points if tariffs are at $20 \%$. The marginal effect of an increase in demand shocks is to reduce the probability that a plant exits by 2.2 percentage points if tariffs are at $60 \%$, and by 2.4 percentage points if tariffs are at $20 \%$. Similarly, the marginal effect of an increase in material prices goes from 1.9 to 2.8 percentage points. The estimated effect of a change in energy prices more than doubles when moving from $60 \%$ to $20 \%$ tariffs, and while each individual effect is insignificant their difference is significant at the $10 \%$ level. As mentioned before, the average exit rate is $9 \%$, so that

\footnotetext{
${ }^{35}$ Given the large changes in tariffs we are evaluating, we follow this approach rather than calculating the cross derivative of the probability of exit with respect to the fundamental and to tariffs, as suggested by Ai and Norton (2003).
} 
these predicted effects are large relative to the average exit probability.

Columns (4)-(6) of Table 6 show results when the market fundamentals for demand are drawn from the specification that permits the demand elasticity to vary across plants. This permits exploring the interaction of tariff reductions with both demand shocks and demand elasticities. The results for TFP and input prices are almost the same as those in Columns (1)-(3), so we focus our remarks on the impact of the demand shocks and demand elasticity. While we obtain about the same results for the demand shock in this specification, the estimated impact of the tariff change moves from being marginally significant to marginally insignificant. Yet, the results for the demand elasticity are insignificant in this interacted specification. Our interpretation is that this interacted specification pushes the data too hard in requiring a lot of variation in the regressors, and our demand elasticity variation is limited. For the other market fundamentals like TFP, input prices, and demand shocks, our estimation methodology yields large and idiosyncratic variation in the fundamentals across plants. In contrast, the demand elasticity varies across plants based upon the road density of the region. We think the latter makes sense and yields interesting patterns in Tables 3 and 5 but likely yields insufficient variation in the estimated elasticity across plants to identify the interaction effect of interest. ${ }^{36}$

In what follows, we conduct a series of counterfactual exercises to illustrate the quantitative implications of Table 6. For this purpose, we use the results from Columns (1)-(3). As noted, both the specifications with and without the demand elasticity in Table 6 yield a clear picture of the interaction between the change in fundamentals and the change in tariffs for TFP, which is the primary focus of the remainder of the analysis. Similarly, the specifications with and without the demand elasticity show essentially the same results for productivity and input prices. In addition, both panels yield similar patterns for demand shocks but with greater precision when the elasticity is left out.

As a summary measure of the overall impact of these interaction effects, we conducted the following counterfactual. Using the estimated probability of exit specification, we compare the plant-level predicted probability of exit when tariffs take on their actual values in each year to the predicted probability of exit when we fix tariffs at their highest levels, i.e., their 1984 levels (all other explanatory variables are held at their mean values under both scenarios). Figure 2 shows this comparison and indicates that the mean predicted probability of exit would had been higher every year with the actual

\footnotetext{
${ }^{36} \mathrm{An}$ important area for future work should be to develop richer demand structures that permit quantifying the variation in demand elastities in a more precise manner across plants.
} 
tariffs than if tariffs had stayed at their 1984 levels, with the difference (the dotted line) being particularly acute during the 1990s. The difference between these two predictions is in the 0.6 to 1 percentage point range during the 1990s - again a large effect relative to the average exit rate of $9 \%$. Note as well that this counterfactual is static in the sense that the $t-1$ market fundamentals are used to predict exit in period $t$, and likely understates the effect of reform by not looking at the cumulative effects of reform. By contrast, below we undertake a dynamic counterfactual simulation which accounts for the cumulative effects.

Before proceeding to the implications of the dynamic analysis for aggregate productivity in the next section, it is useful to note that we conducted a number of robustness checks of the results in Tables 5 and $6 .{ }^{37}$ One possible concern is that the variation in tariff reductions across sectors is endogenous. To address this possibility, we constructed sectoral Herfindahl indices and dropped the $20 \%$ most concentrated 4-digit sectors in our sample according to this index. We do this to dispel concerns that, even though tariffs are measured at the sector- rather than the plant-level, in very concentrated sectors individual establishments could had influenced the tariff rate in the sector. The results are remarkably similar to those that include even the most concentrated sectors in the sample. In addition, it is important to point out that the correlation between the Herfindhal index and tariffs is -0.05 and insignificant. If the lobbying story was behind the higher tariffs in a sector, we would expect the correlation between the Herfindhal Index and tariffs to be positive and significant. In addition, we checked the robustness of our results to alternative measures of tariffs. As an alternative, we substituted the main effect and interactions terms of effective tariffs for nominal tariffs and the results are in general very similar. The exception is the change in the marginal effect of demand shocks induced by the trade liberalization, which lacks statistical significance when using nominal tariffs. ${ }^{38}$

In addition, we explored concerns about biases in the estimation of shocks and demand elasticities due the possibility that product quality and TFP move together. First, we estimated the correlation between TFP and relative prices and dropped the 4-digit sectors with the top $20 \%$ correlations (i.e. those exhibiting less negative correlations) which may be presumably the sectors where TFP and product quality move together.

\footnotetext{
${ }^{37}$ The results are not shown but are available upon request.

${ }^{38}$ We prefer the effective tariffs measure because it captures the total effect of trade liberalization including the effect of competition in the output market as well as increased access to input markets, while nominal tariffs only capture the first effect.
} 
The effects of all fundamentals on exit remain similar in size and significance in this version of the estimation; some of the changes in those effects induced by trade liberalization are estimated less precisely, probably due the smaller sample -close to $1 / 4$ of our observations are lost in this robustness check. Second, to address the potential biases in the estimation of demand shocks and elasticities, we estimate the interacted model (5), but leaving out the level and interaction effects of the demand shocks and elasticities and including instead level and interaction effects of the output price. The results are similar though, not surprisingly, less precise since, as noted in Table 2, TFP and output prices are strongly negatively correlated. Finally, we explored whether the impact of trade reforms takes time to have an impact by including the change in tariffs (in addition to the tariff level) in the specification. We found that the results reported in Table 6 are robust to inclusion of the change of tariffs as an additional explanatory variable and the latter was by itself not significant.

Finally, it is natural to ask whether our analysis sheds light on the impact of other reforms. The specification that underlies the analysis in Table 6 includes other reforms and the interaction of other reforms with market fundamentals so that we can, in principle, conduct an analysis of other reforms in an analogous fashion. We have explored this possibility in unreported results by quantifying the interactions of other reforms with market fundamentals. In this analysis, we find little systematic impact of other reforms in terms of their interaction with market fundamentals. We note, however, caution in interpreting these findings since the other reform measure only varies over time. As such, and quite different from our analysis of trade reform, we are not able to exploit variation in reforms across both sectors and time. Put differently, our primary motivation for including the other reforms variables in the specification underlying Table 6 is to include controls for the overall time series changes in market reform. In that respect, we can interpret the results in Table 6 and the subsequent analysis as holding those time series patterns constant.

\section{Effects of Tariffs on Average Productivity}

In this section we explore various channels through which tariffs and increased foreign competition may have affected average productivity in the manufacturing sector. Given our focus in this paper on plant exit and market selection, we first investigate the implications of our findings on improved market selection for average productivity. However, to put our findings into perspective given other channels and other findings in the liter- 
ature, we also explore whether greater international competition increased productivity by changing the behavior of incumbent establishments. First, trade liberalization may yield within plant increases in productivity through a variety of effects including incentives to invest in technology in response to increased competition and greater exposure to the world production technology frontier. Second, reduced distortions can lead to an improvement in the overall allocation of activity. That is, increased competition is likely to move production from low towards high productivity plants, strengthening the correlation between market share and plant-level productivity. As we have noted in the introduction, there are a number of papers that have explored such channels (including, Baggs (2005), Trefler (2004), Pavcnik (2002), Head and Ries (1999), and Gibson and Harris (1996)). Our value added here is that we use this exploration of alternative channels to help put our results on market selection into perspective. In addition, our results are the first to use measures of plant-level physical productivity in this context and one of the few papers to use tariff measures at a fine level of disaggregation. ${ }^{39}$

\subsection{Trade Induced Exits and Productivity}

The analysis on exits above suggests that trade reform made productivity (and other market fundamentals) more important in determining which plants remain in operation. These results imply that greater competition due to trade liberalization is weeding out the least productive plants and keeping the most productive plants in operation. Thus, one may expect market selection to contribute to increased average productivity. This contribution is likely cumulative since weeding out low productivity plants in a given year implies that market selection in subsequent years will be based on an already improved and select sample of plants.

\footnotetext{
${ }^{39}$ Beyond the channels we explore there are a number of additional channels in the literature whereby trade liberalization impacts plant performance through the availability of new inputs, either novel varieties or higher quality. Recent evidence shows that trade liberalization in India generated gains through the expansion of product and input varieties. Goldberg, Khandelwal, Pavcnik and Topalova (2009) document this on the input side, and Goldberg, Khandelwal, Pavcnik and Topalova (2008) on the output side. Also, Kugler and Verhoogen (2009) present evidence consistent with higher quality of imported inputs, beneficial for higher productivity manufacturers. At the same time, Amiti and Konings (2007) find evidence that the more intensive use of imported inputs due to trade liberalization is associated with higher productivity among manufacturers in Indonesia; and Halpern, Koren and Szeidl (2005) provide similar evidence for Hungary. While our paper does not analyze these channels directly, our use of effective, rather than nominal, tariffs takes into account improved access to imported inputs.
} 
In this section, we investigate the possible contribution of trade reforms to average plant-level productivity via a selection effect. Focusing on the selection effect alone, we generate an estimate of average plant-level productivity under two alternative selection scenarios. Under one scenario, we use the actual values of tariffs to predict exit using our estimated selection model, and estimate the implied path of average productivity. Under the second scenario, we set tariffs at their 1984 value and then generate the dynamic path of selection that would have occurred from 1985 onwards. ${ }^{40}$ Since productivity, demand and input cost shocks were also changing during the period, we carry out a dynamic simulation of the exit process of Colombian plants that allows us to hold the contribution of changes in the shock processes constant.

Our dynamic simulation works as follows. First, we take the set of plants in 1985 with their actual values of fundamentals. We use the estimated probit model in (5) to generate a predicted set of exiters and survivors for 1986. Note that 1985 is the first year for which we have all the determinants of exit included in equation (5), which is why we use 1985 to initialize our simulation. In generating the predicted exiters and survivors, we assign all plants at risk a value of 0 (exit) or 1 (survive) by taking appropriate random draws from a binary distribution with the estimated probability of exit. Under one scenario the tariffs are set at the 1985 (true) values and under the other scenario the tariffs are set at the 1984 values. For the establishments that are predicted to survive, we then generate the 1986 fundamentals using $\mathrm{AR}(1)$ processes estimated for each fundamental (i.e., TFP, demand shocks, cost shocks) using the entire sample of plants. ${ }^{41}$ We then add, to that set of plants, the actual 1986 entrants with their actual value of fundamentals. Next, we repeat the simulation of exit and survival - again using, alternatively, the 1986 (true) tariffs and the 1984 tariffs. We continue this process iteratively for all plants, allowing us to generate two counterfactual distributions of plants up to 1998.

Using these two counterfactual distributions of plants, we calculate key moments of the distribution of TFP. In particular, we calculate the path of average productivity for each year for the two dynamic simulations. We note that since the shock processes for fundamentals are being held constant in these dynamic simulations, any difference in average TFP between the two scenarios responds to differences in the exit process

\footnotetext{
${ }^{40}$ The 1984 tariffs were the highest tariffs observed during our entire sample period.

${ }^{41}$ The AR(1) processes assume a mean-zero normally distributed error. Our projections based on these processes include a random draw of a mean zero normal distribution, with the standard deviation of the residuals from the $\mathrm{AR}(1)$ estimation for each of the fundamentals.
} 
associated with the alternative trade policies.

Our results are reported in Table 7 . Column (1) reports the means and standard deviations of the log of TFP when the exit process assumes that tariffs are at their actual levels for each 4-digit industry for the entire sample of plants. Column (2) reports the mean for the case in which exit is projected keeping tariffs at their 1984 values. Finally, Column (3) reports the difference between these two columns and t-statistics for these mean differences in square brackets. We conduct these simulations for all years as described above. In reporting the results, we find it instructive to report results for pooled years so that we compare and contrast the period when tariffs remained relatively high, 1986-1991, to the period during which tariffs were substantially reduced, 1992-1998. Our results indicate that the change in tariffs from the initial 1984 level generate insignificant gains in average TFP between 1986 and 1991. By contrast, the results show a large gain in average TFP between 1992 and 1998 of 3.3 log points which is significant at the $1 \%$ level for the entire sample of plants. As a separate, but closely related experiment, we repeat these dynamic simulations but exclude the entrants from the analysis to explore the extent to which the differences in selection across the two scenarios yields differences for the 1985 incumbents only and also changes in entry selectivity. The results in Columns (4)-(6) of Table 7 show smaller gains in TFP from the reduction in tariffs relative to the 1984 level when the simulation is carried out for the 1985 incumbents alone. This suggests that better market selection of recent entrants after tariffs go down is an important channel through which trade has a positive impact on productivity.

Table 8 shows that this change in average TFP is, indeed, driven partly by the weeding out of less efficient plants. Columns (1) and (2) in Table 8 report the mean, standard deviation, and the 1st and 50th percentiles of the simulated TFP in 1998 for the sample of plants predicted to survive up to that year given the actual and 1984 tariffs, respectively. The simulated TFP for plants in the lowest percentile of simulated TFP has a cut point 8 log points higher when choosing the plants predicted to survive with actual tariffs compared to when the 1984 tariffs are used, consistent with lower tariffs increasing productivity at the lower end of the distribution. While we also observe higher productivity at the median when choosing the plants predicted to survive with actual instead of the 1984 tariff levels, the difference is much smaller than for the first percentile (less than half a log point).

To put the results in Tables 7 and 8 into perspective, we note that over the 1992 to 1998 period the average industry in Colombia experienced an increase in total factor 
productivity of $12 \log$ points (Eslava et al. (2004)). From that perspective, increases in average productivity of $3 \%$ from a change in the market selection process driven by trade reform alone are substantial.

\subsection{Effects of Trade on Reallocation and Productivity Growth of Incumbents}

While the focus in our paper has been on the impact of trade on plant exits and, in turn, on productivity, we are also interested in examining the impact of reduced tariffs on the productivity of continuing establishments.

First, continuing plants may be induced to become more productive through increased international competition and greater exposure to best practices world-wide. To examine this hypothesis, we estimate a simple differences-in-differences specification regressing the log first difference of TFP for continuing plants on year effects, detailed industry effects and the change in tariffs (at the 4-digit level). This specification is analogous to a similar exercise in Pavcnik (2002). Results are presented in Panel 1 of Table 9. We find evidence that continuing plants in industries with larger tariff reductions have greater within plant growth rates in productivity. The point estimate suggests that reducing tariffs from 60 to 20 percent (approximately the average size of the tariff reduction) would yield a within plant increase in productivity of about 2.8 log points. This within plant effect is smaller than the increase in average plant productivity we estimated from selection. Put together with the results in the prior section, the trade reforms appear to increase average plant-level productivity both by cutting off the lower tail of the productivity distribution and by increasing productivity among continuing plants.

Second, trade reform may have improved the overall allocation of activity. ${ }^{42} \mathrm{We}$ examine the impact of trade opening on the reallocation of activity by conducting both plant-level and sectoral-level analyses. Both of these analyses should be interpreted as providing insights into how the level of tariffs impacts the correlation between market share and productivity. At the plant-level, we regress the share of the plant's output in its 3-digit sector on productivity, tariffs and the interaction of tariffs and productivity

\footnotetext{
${ }^{42}$ While the shedding of less productive plants may be one reason for an improvement of the allocation of activity, more dynamic internal adjustments for incumbent plants and entry of establishments that are more productive or quickly become more productive may also work in the same direction. In this sense, the analysis of the size-productivity correlation after reform conducted in this section is broader than the analysis of plant exit above.
} 
while also controlling for sector and year effects. The results reported in Panel 2 of Table 9 show that lower tariffs increase the correlation between plant-level productivity and market share, i.e., the coefficient on the interaction term of tariffs and productivity is negative. The point estimates imply that a reducing tariffs from 60 to 20 percent increases the correlation from 0.30 to 0.36 .

Similarly, we can use the Olley and Pakes (1996) (OP) sectoral decomposition methodology to compute the covariance between market share and plant-level productivity for every 3-digit sector in each year. We then estimate a simple differences-in-differences specification with the dependent variable being the 3-digit yearly OP cross-term and the explanatory variables including industry effects, year effects and 3-digit tariffs. Column (2) of Panel 3 of Table 9 shows that sectors with lower tariffs experience a larger increase in the OP cross-term. The point estimate suggests that reducing tariffs from 60 to 20 percent increases the OP cross-term by 7.8 log points. This improved allocation is a large effect relative to either the within plant increases for continuing plants and the market selection effects discussed above. Note however that this reallocation effect is partly driven by the market selection effects we discuss above. That is, more productive plants may increase their market share not only at the expense of less productive continuing plants but also at the expense of less productive plants which exited the market.

Finally, we note that this simple difference-in-difference methodology can be used with overall industry level productivity to quantify the overall effect of trade reforms on industry productivity. The first column in Panel 3 of Table 9 shows the results for this specification. This exercise indicates that a reduction in tariffs from 60 percent to 20 percent increases average industry productivity by $8.2 \mathrm{log}$ points. The latter effect is the combined effect of improved average plant-level productivity and improved allocation, where as discussed improved allocation accounts for 7.8 of the total 8.2 improvement. As indicated, there is no exact decomposition of the role of market selection in this context since it contributes to both increases in average plant-level productivity (the results in the prior section) and improvements in allocation. Finding the overall contribution of market selection would require more structure in modeling both the changes of productivity and market shares of incumbents and the contribution of entering and exiting plants. 


\section{Conclusion}

We find that plant profit margin fundamentals are important determinants of plant exits. Our analysis goes further than the existing literature by analyzing the impact of a rich set of profit margin fundamentals rather than relying on proxies. In particular, we find that higher physical productivity, higher demand, lower input costs and higher mark-ups reduce the probability that plants exit. In exploring the role of trade reforms, we find that lower effective tariffs increase the marginal impact of productivity, demand shocks and input costs on plant exit. As a result, lower effective tariffs have changed the nature of market selection and increased exit during the period of trade reform in Colombia.

Given that all these findings point towards a greater impact of competitive forces on plant selection due to trade reform, we then investigate the implied impact on average productivity. For this purpose, we conduct counter-factual exercises that show what productivity would had been if plant survival had continued as with the 1984 tariffs compared to actual tariff levels. In particular, we quantify the implied average plantlevel productivity using plant exit probabilities holding tariffs at their beginning of the period levels and at their actual levels. Average plant-level productivity is about $3.3 \log$ points higher than it would have been in the absence of improved market selection. This effect is substantial relative to the overall rise in average productivity of 12 log points over this post reform period (Eslava et al. (2004), comparing aggregate TFP in 1992 to 1998).

The results, thus, suggest a truncation of the productivity distribution on the left due to greater exit of less productive plants after trade reforms. Our findings are consistent with the prediction in the Melitz (2003) and Bernard et al. (2003) models, and other related models, of an increase in the productivity threshold required for plant survival after trade liberalization. This is consistent with Trefler's (2004) study, which finds that trade liberalization increases productivity in Canada. However, in contrast to our study, Trefler's study does not focus on the impact of profit margin fundamentals on exit or on the impact of trade on market selection.

Moreover, we also find that trade reform is associated with an increase in within plant productivity growth for incumbent plants and improved allocation of activity within sectors. We estimate that the impact of the Colombian trade liberalization of the early nineties on incumbent plant productivity growth is 2.8 log points, while it impact on overall within sector reallocation is $7.8 \mathrm{log}$ points. These latter findings are also quan- 
titatively important and fit in with the overall story of improved market competition yielding increases in productivity through a variety of complementary channels. The point that there are many potential channels of the impact of trade liberalization and other reforms on productivity both at the plant- and the industry- levels must not be understated. We believe our current findings highlight the importance of market selection as a channel for trade liberalization to improve productivity. A challenge for future work is to find ways of integrating and assessing the relative importance of the many alternative channels through which trade liberalization, and more generally market reforms, may impact the industrial structure of an economy. 


\section{References}

[1] Ai, Chunrong and Edward Norton. 2003. "Interaction terms in logit and probit models," Economics Letters, 80: 123-129.

[2] Amiti, Mary and Jozef Konings. 2007. "Trade Liberalization, Intermediate Inputs and Productivity," American Economic Review, 97(5), 1611-1638.

[3] Attanasio, Orazio, Pinelopi Goldberg and Nina Pavcnik. 2004. "Trade Reforms and Wage Inequality in Colombia," Journal of Development Economics, 74(2): 331-366.

[4] Baggs, Jen. 2005. "Firm Survival and Exit in Response to Trade Liberalization," Canadian Journal of Economics, 38(4): 1364-1383.

[5] Baily, Martin, David Campbell and Charles Hulten. 1992. "Productivity Dynamics in Manufacturing Establishments," Brookings Papers on Economic Activity: Microeconomics, 187-249.

[6] Banerjee, Abhijit and Esther Duflo. 2005. "Growth Theory through the Lens of Development Economics," Handbook of Economic Growth, eds., Steve Durlauf and Philippe Aghion, Vol. 1A.

[7] Bartelsman, Eric, John Haltiwanger and Stefano Scarpetta. 2008. "Cross Country Differences in Productivity: The Role of Allocative Efficiency," Mimeo.

[8] Bernard, Andrew B., Jonathan Eaton, J. Bradford Jensen, and Samuel Kortum. 2003. "Plants and Productivity in International Trade," American Economic Review, 93(4), 1268-1290.

[9] Bernard, Andrew and J. Bradford Jensen. 2007. "Firm Structure, Multinationals and Manufacturing Plants Death," Review of Economics and Statistics, 89(2): 193204.

[10] Blundell, Richard and Stephen Bond. 1998. "Initial Conditions and Moment Restrictions in Dynamic Panel Data Models," Journal of Econometrics, 87(1): 115143.

[11] Davis, Steven, John Haltiwanger and Scott Schuh. 1996. Job Creation and Destruction. Cambridge, Mass.: MIT Press. 
[12] Ericson, Richard and Ariel Pakes. 1995. "Markov-perfect Industry Dynamics: A Framework for Empirical Work," Review of Economic Studies, 62: 53-82.

[13] Eslava Marcela, John Haltiwanger, Adriana Kugler and Maurice Kugler. 2009. "Factor Adjustments after Deregulation: Panel Evidence from Colombian Plants," forthcoming in Review of Economics and Statistics.

[14] Eslava Marcela, John Haltiwanger, Adriana Kugler and Maurice Kugler. 2006. "Plant Turnover and Structural Reforms in Colombia," IMF Staff Papers, 53: 5875 .

[15] Eslava Marcela, John Haltiwanger, Adriana Kugler and Maurice Kugler. 2004. "The Effects of Structural Reforms on Productivity and Profitability Enhancing Reallocation: Evidence from Colombia," Journal of Development Economics, 75(2): 333371.

[16] Fernandes, Ana. 2007. "Trade Policy, Trade Volumes and Plant-Level Productivity in Colombian Manufacturing Industries," Journal of International Economics, 71(1): 52-71.

[17] Foster, Lucia, John Haltiwanger, and Cornell Krizan. 2001. "Aggregate Productivity Growth: Lessons from Microeconomic Evidence," in Edward Dean Michael Harper and Charles Hulten, eds., New Developments in Productivity Analysis. Chicago: University of Chicago Press.

[18] Foster, Lucia, John Haltiwanger, and Chad Syverson. 2008. "Reallocation, Firm Turnover, and Efficiency: Selection on Productivity or Profitability?," American Economic Review, 98(1): 394-425.

[19] Gibson, John and Richard Harris. 1996. "Trade Liberalisation and Plant Exit in New Zeland Manufacturing," Review of Economics and Statistics, 78(3): 521-529.

[20] Goldberg, Pinelopi K., Amit Khandelwal, Nina Pavcnik and Petia Topalova. 2008. "Imported Intermediate Inputs and Domestic Product Growth: Evidence from India," NBER Working Paper No. 14416.

[21] Goldberg, Pinelopi K., Amit Khandelwal, Nina Pavcnik and Petia Topalova. 2009. "Trade Liberalization and New Imported Inputs," forthcoming in American Economic Review, Papers and Proceedings. 
[22] Goldberg, Pinelopi and Nina Pavcnik. 2005. "Trade, Wages, and the Political Economy of Trade Protection: Evidence from the Colombian Trade Reforms," Journal of International Economics, 66(1): 75-105.

[23] Goldberg, Pinelopi and Nina Pavcnik. 2007. "Distributional Effects of Globalization in Developing Countries," Journal of Economic Literature, 45(1): 39-82.

[24] Halpern, Lazlo, Miklos Koren and Adam Szeidl. 2005. "Imports and Productivity," CEPR Discussion Paper No. 5139.

[25] Harrison, Anne. 1994. "Productivity, Imperfect Competition and Trade Reform," Journal of International Economics, 36(1/2): 53-73.

[26] Head, Keith and John Ries. 1999. "Rationalization Effects of Tariff Reductions," Journal of International Economics, 36(1): 53-73.

[27] Hsieh, Chang-tai and Peter Klenow. 2009. "Misallocation and Manufacturing TFP in China and India," forthcoming in Quarterly Journal of Economics.

[28] Hopenhayn, Hugo. 1992. "Entry, Exit, and Firm Dynamics in Long Run Equilibrium," Econometrica, 60(5): 1127-50.

[29] Jovanovic, Boyan. 1982. "Selection and the Evolution of Industry," Econometrica, 50(3): 649-670.

[30] Kugler, Adriana and Maurice Kugler. 2009. "Labor Market Effects of Payroll Taxes in Developing Countries: Evidence from Colombia," Economic Development and Cultural Change, 57(2): 335-358.

[31] Kugler, Adriana. 2005. "Wage-Shifting Effects of Severance Payments Savings Accounts in Colombia," Journal of Public Economics, 89(2-3): 487-500.

[32] Kugler, Adriana. 1999. "The Impact of Firing Costs on Turnover and Unemployment: Evidence from the Colombian Labor Market Reform," International Tax and Public Finance Journal, 6: 389-410.

[33] Kugler, Maurice. 2006. "Spillovers from Foreign Direct Investment: Within or Between Industries?," Journal of Development Economics, 80(2): 444-477. 
[34] Kugler, Maurice and Eric Verhoogen. 2009. "Plants and Imported Inputs: New Facts and an Interpretation," forthcoming in American Economic Review, Papers and Proceedings.

[35] Levinsohn, James. 1993. "Testing the Imports-as-Market-Discipline Hypothesis," Journal of International Economics, 36(1/2): 1-22.

[36] Lora, Eduardo. 2001. "Structural Reforms in Latin America: What Has Been Reformed and How to Measure It," Inter-American Development Bank Working Paper No. 466.

[37] Melitz, Marc. 2003. "The Impact of Trade on Intra-Industry Reallocations and Aggregate Industry Productivity," Econometrica, 71(6): 1695-1726.

[38] Melitz, Marc and Gianmarco Ottaviano. 2008. "Market Size, Trade, and Productivity," Review of Economic Studies, 75(1): 295-316.

[39] Olley, Steven and Ariel Pakes. 1996. "The Dynamics of Productivity in the Telecommunications Equipment Industry," Econometrica, 64(6): 1263-1310.

[40] Pavcnik, Nina. 2002. "Trade Liberalization, Exit, and Productivity Improvements: Evidence from Chilean Plants," Review of Economic Studies, 69: 245-76.

[41] Pombo, Carlos. 1999. "Productividad Industrial en Colombia: Una Aplicacion de Numeros Indices," Revista de Economia del Rosario.

[42] Restuccia, Diego and Richard Rogerson. 2008. "Policy Distortions and Aggregate Productivity with Heterogeneous Plants," Review of Economic Dynamics, 11(October): $707-720$.

[43] Topalova, Petia. 2004. "Trade Liberalization and Firm Productivity: The Case of India," IMF Working Paper No. 04/28.

[44] Trefler, Daniel. 2004. "The Long and Short of the Canada-U.S. Free Trade Agreement," American Economic Review, 94(4): 870-895.

[45] Tybout, James. 2000. "Manufacturing Firms in Developing Countries: How Well Do They Do, And Why?," Journal of Economic Literature, 38(1): 11-34. 
[46] Tybout and Westbrook (1995), "Trade Liberalization and Dimensions of Efficiency Change in Mexican Manufacturing Industries," Journal of International Economics, 39 (August), pp. 53-78.

[47] Van Biesebroeck, J. (2008), "The Sensitivity of Productivity Estimates: Revisiting Three Important Productivity Debates," Journal of Business and Economic Statistics, 26(3): 321-238.

[48] Woolridge, Jeffrey. 2002. Econometric Analysis of Cross Section and Panel Data. Cambridge: MIT Press. 
Table 1: Descriptive Statistics

\begin{tabular}{lc}
\hline Variable & \\
\hline Output & 10.71 \\
& $(1.75)$ \\
Capital & 8.43 \\
& $(2.09)$ \\
Labor & 10.98 \\
& $(1.16)$ \\
Energy & 11.44 \\
Materials & $(1.89)$ \\
& 9.92 \\
Output Prices & $(1.87)$ \\
& -0.11 \\
Energy Prices & $(0.58)$ \\
& 0.37 \\
Material Prices & $(0.49)$ \\
& -0.03 \\
Entry Rate & $(0.46)$ \\
& 0.07 \\
Exit Rate & $(0.25)$ \\
& 0.09 \\
N & $(0.28)$ \\
\hline \hline
\end{tabular}

Notes: This table reports means and standard deviations of the log of quantities and of log price indices deviated from yearly log producer price indices. The sample has been restricted to plants in three-digit sectors that have reports for more than 25 plants per year in average, and to plants also included in Table 2 (those for which TFP can be calculated). The entry and exit rates are the number of entrants divided by total plants and number of exiting plants divided by total number of plants. A plant that enters in $\mathrm{t}$ is defined as a plant that reported positive production in $\mathrm{t}$ but not in $\mathrm{t}-1$, while a plant that exits in $\mathrm{t}$ is one that reported positive production in $\mathrm{t}$ but not in $\mathrm{t}+1$. 
Table 2: Descriptive statistics for different measures of TFP

\begin{tabular}{|c|c|c|c|c|c|c|}
\hline \multirow{3}{*}{ TFP Measure } & \multirow{3}{*}{$\begin{array}{l}\text { Standard } \\
\text { deviation }\end{array}$} & \multicolumn{5}{|c|}{ Correlation Coefficients Matrix } \\
\hline & & TFP & TFP2 & TFPC & TFPO & RP1 \\
\hline & & (1) & (2) & (3) & (4) & (5) \\
\hline TFP & 0.7668 & 1 & 0.69 & 0.90 & 0.86 & -0.65 \\
\hline $\begin{array}{l}\text { TFP deflating output and materials } \\
\text { with sector-level prices (TFP2) }\end{array}$ & 0.6079 & & 1 & 0.53 & 0.40 & -0.00 \\
\hline $\begin{array}{l}\text { TFP with factor elasticities equal to } \\
\text { cost shares (TFPC) }\end{array}$ & 0.7657 & & & 1 & 0.86 & -0.64 \\
\hline $\begin{array}{l}\text { TFP with factor elasticities from } \\
\text { OLS (TFPO) }\end{array}$ & 0.6620 & & & & 1 & -0.72 \\
\hline Output prices relative to PPI (RP1) & 0.5604 & & & & & 1 \\
\hline $\mathrm{N}$ & & 85,203 & 85,203 & 85,203 & 85,203 & 85,203 \\
\hline
\end{tabular}

Notes: This table reports standard deviations and correlation coefficients for different measures of TFP and for the plant-level output prices. All figures are simple means of statistics calculated at the 3-digit sector level. The exception is the total number of observations for the calculation of each correlation coefficient, reported in the last line, which includes all sectors. The factor elasticities used to estimate TFP (Column (1)) are obtained from a 2SLS estimation of the production function, as described in the text. The equivalent factor elasticities used for TFPC (Column (3)) are cost shares calculated at the three-digit sector level. For Column (4), factor elasticities are obtained from an OLS estimation of the production function. Meanwhile, TFP2 in Column (2) uses the same factor elasticities as in column (1), but the price indices used to deflate output and materials are calculated at the three-digit sector level rather than at the plant level. Sector level price indices are calculated as the geometric mean of plant level price indices for a given 3-digit sector, using output shares as weights. Relative output prices RP1 are constructed as the log difference between plant level price indices and the aggregate log Producer Price Index, and reported in Column (5). 
Table 3: Demand Estimation

\begin{tabular}{|c|c|c|c|}
\hline Regressor & $\begin{array}{l}\text { OLS } \\
(1) \\
\end{array}$ & $\begin{array}{c}\text { 2SLS } \\
(2) \\
\end{array}$ & $\begin{array}{c}\text { 2SLS } \\
(3) \\
\end{array}$ \\
\hline Relative Price & $\begin{array}{c}-0.8735^{* * *} \\
(0.0100)\end{array}$ & $\begin{array}{c}-2.1209^{* * *} \\
(0.0194) \\
{[0.3852]}\end{array}$ & $\begin{array}{c}-1.7305^{* * *} \\
(0.0594) \\
{[0.3932]}\end{array}$ \\
\hline $\begin{array}{l}\text { Relative Price } \\
\times \text { Road Density }\end{array}$ & & & $\begin{array}{c}-1.2379^{* * *} \\
(0.2213) \\
{[0.3625]}\end{array}$ \\
\hline Road Density & & & $\begin{array}{c}1.8250{ }^{* * *} \\
(0.2030) \\
{[1.0000]}\end{array}$ \\
\hline $\begin{array}{l}\text { Sector Effects } \\
\text { Region Effects }\end{array}$ & $\begin{array}{c}\text { YES } \\
\text { NO } \\
1.6169\end{array}$ & $\begin{array}{c}\text { YES } \\
\text { NO } \\
1.7689\end{array}$ & $\begin{array}{c}\text { YES } \\
\text { YES } \\
1.7199\end{array}$ \\
\hline Root MSE & 73,697 & 73,697 & 73,697 \\
\hline
\end{tabular}

Notes: This table reports results from estimating demand functions. Robust standard errors are in parentheses. The 2SLS in Columns (2) and (3) use TFP as an instrument for the relative price. First Stage $\mathrm{R}^{2}$ is in square brackets. The dependent variable is physical output in logs, and the regressor "Relative Price" is the log difference between plant-level price and the yearly PPI. The estimated coefficients do not vary across sectors, but all regressions include 2-digit sector dummies. The two-stage least squares regression in Column (3) includes region fixed effects. The two-stage least squares regression in Column (2) instruments price with the 2SLS TFP measure, lagged one period. The road density measure included in Column (3) is the kilometers of paved roads per squared kilometer of area in the state in which the plant is located. An interaction between this index and the relative price is also included. This interaction is instrumented using an interaction between the plant's TFP (lagged) and the road density index. The regression in Column (3) also controls for aggregate activity, given potential correlation with the increasing coverage of roads over time. Some observations are lost with respect to Table 2 due to lack of information on road density. * indicates significance at the $10 \%$ level, ** indicates significance at the $5 \%$ level and *** indicates significance at the $1 \%$ level. 
Table 4: Descriptive Statistics of Determinants of Survival

\begin{tabular}{lc}
\hline \hline Variable & \\
\hline & 1.1745 \\
Lagged TFP & $(0.7765)$ \\
Lagged Demand Shock & 10.6125 \\
(Column 2 Table 3) & $(1.8268)$ \\
Lagged Demand Shock & 10.6468 \\
(Column 3 Table 3) & $(1.8231)$ \\
Lagged Demand Elasticity & -2.0428 \\
(Column 3 Table 3) & $(0.1492)$ \\
& 0.4508 \\
Reforms Other than Trade & $(0.1220)$ \\
Effective Tariffs & 0.5599 \\
& $(0.3854)$ \\
GDP Growth & 0.0408 \\
N & $(0.0121)$ \\
\hline \hline
\end{tabular}

Notes: This table reports means and standard deviations of the variables used to estimate exit probabilities. TFP is calculated using factor elasticities from a 2SLS estimation procedure, while demand shocks and demand elasticities come from the estimations reported in Table 3. The Index of Other Reforms is constructed using all components of the Lora Overall Reform Index, except those included in the Trade Index. Each of the sub-components of Lora's index has been re-scaled to be 0 in the year of less liberalization in Colombia and 1 in the year of most liberalization in Colombia. Effective Tariffs are available at the four-digit level, calculated from data by the National Planning Department. The sample is restricted to observations that enter the regressions in Tables 5 and 6. 
Table 5: Determinants of Exit Probability

\begin{tabular}{|c|c|c|c|c|}
\hline & $(1)$ & $(2)$ & $(3)$ & $(4)$ \\
\hline Lagged Productivity & $\begin{array}{l}-0.0161^{* * *} \\
(0.0015)\end{array}$ & $\begin{array}{l}-0.0300^{* * *} \\
(0.0021)\end{array}$ & $\begin{array}{l}-0.0169^{* * *} \\
(0.0015)\end{array}$ & $\begin{array}{l}-0.0157^{* * *} \\
(0.0015)\end{array}$ \\
\hline Lagged Energy Prices & $\begin{array}{l}0.0070^{* * *} \\
(0.0023)\end{array}$ & $\begin{array}{c}0.0084^{* * *} \\
(0.0022)\end{array}$ & $\begin{array}{l}0.0077^{* * *} \\
(0.0021)\end{array}$ & $\begin{array}{l}0.0070^{* * *} \\
(0.0021)\end{array}$ \\
\hline Lagged Materials Prices & $\begin{array}{l}0.0129^{* * *} \\
(0.0028)\end{array}$ & $\begin{array}{l}0.0219^{* * *} \\
(0.0030)\end{array}$ & $\begin{array}{l}0.0178^{* * *} \\
(0.0026)\end{array}$ & $\begin{array}{l}0.0176^{* * *} \\
(0.0026)\end{array}$ \\
\hline Lagged Output Prices & & $\begin{array}{l}-0.0296^{* * *} \\
(0.0029)\end{array}$ & & \\
\hline $\begin{array}{l}\text { Lagged Demand Shock } \\
\text { (Column } 2 \text { Table } 3 \text { ) }\end{array}$ & & & $\begin{array}{l}-0.0215^{* * *} \\
(0.0007)\end{array}$ & \\
\hline $\begin{array}{l}\text { Lagged Demand Shock } \\
\text { (Column } 3 \text { Table 3) }\end{array}$ & & & & $\begin{array}{c}-0.0217^{* * *} \\
(0.0007)\end{array}$ \\
\hline $\begin{array}{l}\text { Demand Elasticity } \\
\text { (Column } 3 \text { Table 3) }\end{array}$ & & & & $\begin{array}{l}-0.0191^{* * *} \\
(0.0068)\end{array}$ \\
\hline Sector Effects & YES & YES & YES & YES \\
\hline GDP Growth & YES & YES & YES & YES \\
\hline Likelihood Ratio & $\begin{array}{l}529.44 \\
(12 \mathrm{df})\end{array}$ & $\begin{array}{l}599.19 \\
\text { (13df) }\end{array}$ & $\begin{array}{l}1189.45 \\
\text { (13df) }\end{array}$ & $\begin{array}{l}1207.47 \\
(14 d f)\end{array}$ \\
\hline $\mathrm{N}$ & 57,886 & 57,886 & 57,886 & 57,886 \\
\hline
\end{tabular}

Notes: This table reports marginal effects from a Probit estimation of the probability of exit, where exit is $1 \mathrm{for}$ plant $\mathrm{i}$ in year $\mathrm{t}$ if the plant produced in year $\mathrm{t}$ but not in year $\mathrm{t}+1$. Robust standards errors in parentheses. Marginal effects are evaluated at mean values of all the independent variables. All specifications include sector effects at the 2-digit level as well as plant-level productivity, energy prices, and materials prices. Column (2) includes output prices. Column (3) includes a measure of demand shocks estimated using Column (2) in Table 3. Column (4) includes measures of the demand shock and demand elasticity estimated using Column (3) of Table 3. The sample is restricted to observations that enter the regression in Table $6 . *$ indicates significance at the $10 \%$ level, ** indicates significance at the $5 \%$ level and $* * *$ indicates significance at the $1 \%$ level. 
Table 6: Determinants of Exit Probability in a Model with Reforms and Tariffs.

\begin{tabular}{|c|c|c|c|c|c|c|}
\hline & $\begin{array}{c}\text { Ef. Tariffs at } \\
60 \% \\
(1) \\
\end{array}$ & $\begin{array}{c}\text { Ef. Tariffs at } \\
20 \% \\
(2) \\
\end{array}$ & $\begin{array}{c}\text { Difference } \\
(3) \\
\end{array}$ & $\begin{array}{c}\text { Ef. Tariffs at } \\
60 \% \\
(4) \\
\end{array}$ & $\begin{array}{c}\text { Ef. Tariffs at } \\
20 \% \\
(5) \\
\end{array}$ & $\begin{array}{c}\text { Difference } \\
(6) \\
\end{array}$ \\
\hline Lagged Productivity & $\begin{array}{c}-0.0149^{* * *} \\
(0.0016)\end{array}$ & $\begin{array}{c}-0.0200^{* * *} \\
(0.0024)\end{array}$ & $\begin{array}{l}0.0052^{* *} \\
(0.0023)\end{array}$ & $\begin{array}{c}-0.0138^{* * *} \\
(0.0016)\end{array}$ & $\begin{array}{c}-0.0190^{* * *} \\
(0.0024)\end{array}$ & $\begin{array}{l}0.0052^{* *} \\
(0.0023)\end{array}$ \\
\hline Lagged Energy Prices & $\begin{array}{c}0.0004 \\
(0.0023)\end{array}$ & $\begin{array}{c}0.0047 \\
(0.0035)\end{array}$ & $\begin{array}{l}-0.0043 \\
(0.0031)\end{array}$ & $\begin{array}{l}-0.0002 \\
(0.0024)\end{array}$ & $\begin{array}{c}0.0040 \\
(0.0036)\end{array}$ & $\begin{array}{l}-0.0042 \\
(0.0031)\end{array}$ \\
\hline Lagged Materials Prices & $\begin{array}{l}0.0190^{* * *} \\
(0.0027)\end{array}$ & $\begin{array}{l}0.0277^{* * *} \\
(0.0043)\end{array}$ & $\begin{array}{l}-0.0086^{* *} \\
(0.0039)\end{array}$ & $\begin{array}{l}0.0186^{* * *} \\
(0.0027)\end{array}$ & $\begin{array}{c}0.0273^{* * *} \\
(0.0043)\end{array}$ & $\begin{array}{l}-0.0086^{* *} \\
(0.0039)\end{array}$ \\
\hline $\begin{array}{l}\text { Lagged Demand Shock } \\
\text { (Column } 2 \text { Table 3) }\end{array}$ & $\begin{array}{c}-0.0224^{* * *} \\
(0.0007)\end{array}$ & $\begin{array}{c}-0.0242^{* * *} \\
(0.0011)\end{array}$ & $\begin{array}{c}0.0017^{*} \\
(0.0010)\end{array}$ & & & \\
\hline $\begin{array}{l}\text { Lagged Demand Shock } \\
\text { (Column } 3 \text { Table 3) }\end{array}$ & & & & $\begin{array}{c}-0.0228^{* * *} \\
(0.0007)\end{array}$ & $\begin{array}{c}-0.0243^{* * *} \\
(0.0011)\end{array}$ & $\begin{array}{c}0.0016 \\
(0.0010)\end{array}$ \\
\hline $\begin{array}{l}\text { Lagged Demand Elasticity } \\
\text { (Column } 3 \text { Table 3) }\end{array}$ & & & & $\begin{array}{l}-0.0101 \\
(0.0071)\end{array}$ & $\begin{array}{c}0.0030 \\
(0.0126)\end{array}$ & $\begin{array}{l}-0.0131 \\
(0.0116)\end{array}$ \\
\hline Effective Tariffs & $\begin{array}{l}-0.0034 \\
(0.0045)\end{array}$ & $\begin{array}{l}-0.0035 \\
(0.0046)\end{array}$ & $\begin{array}{c}0.0001 \\
(0.0001)\end{array}$ & $\begin{array}{l}-0.0029 \\
(0.0045)\end{array}$ & $\begin{array}{l}-0.0029 \\
(0.0047)\end{array}$ & $\begin{array}{c}0.0000 \\
(0.0001)\end{array}$ \\
\hline Other Reforms Index & YES & YES & & YES & YES & \\
\hline $\begin{array}{l}\text { Interactions with } \\
\text { Other Reforms Index }\end{array}$ & YES & YES & & YES & YES & \\
\hline Sector Effects & YES & YES & & YES & YES & \\
\hline GDP Growth & YES & YES & & YES & YES & \\
\hline $\mathrm{N}$ & 57,886 & 57,886 & 57,886 & 57,886 & 57,886 & 57,886 \\
\hline
\end{tabular}

Notes: This table reports marginal effects and robust standards errors from a Probit estimation of the probability of exit where exit is 1 for plant $\mathrm{i}$ in year $\mathrm{t}$ if the plant produced in year $t$ but not in year $t+1$. Robust errors in parentheses. Marginal effects are evaluated at mean values of all variables, except for effective tariffs. In Columns (1) and (3) effective tariffs are set at a value of $60 \%$, while in Columns (2) and (4) they are set at $20 \%$. Columns (3) and (6) report the difference between effects when tariffs are at $20 \%$ and at $60 \%$. The specification includes sector effects at the 2-digit level, as well as plant-level productivity, energy prices, materials prices and demand shocks and elasticities. Effective tariffs and interactions of effective tariffs with all of the plant-level regressors are also included. Similarly, we include an index of reforms other than trade reform, and interactions of this index with all of the plant-level regressors. The TFP measure is obtained using the factor elasticities from a 2SLS estimation procedure. The demands shock and demand elasticity measures used for this Table come from Table 3. * indicates significance at the $10 \%$ level, ${ }^{* *}$ indicates significance at the $5 \%$ level and ${ }^{* * *}$ indicates significance at the $1 \%$. 
Average $\mathrm{TFP}_{\mathrm{t}}$

(Using Projected $\mathrm{TFP}_{i t}$ for Simulated Continuers and actual TFP ${ }_{i t}$ for Actual Entrants)

All Plants

1985 Incumbents

Sample Actual Tariffs 1984 Tariffs Difference Actual Tariffs 1984 Tariffs Difference (1)

(2)

(3)

(4)

(5)

(6)

\begin{tabular}{lcccccc}
\hline & & & & & & \\
$1986-1991$ & $(0.7947)$ & $(0.7989)$ & {$[0.26]$} & $(0.7837)$ & $(0.7852)$ & {$[0.15]$} \\
& & & & & & \\
& 1.1407 & 1.1080 & 0.0326 & 1.1144 & 1.0683 & 0.0462 \\
$1992-1998$ & $(0.9373)$ & $(0.9275)$ & {$[3.27]$} & $(0.9402)$ & $(0.9031)$ & {$[3.52]$} \\
& & & & & & \\
& 1.1313 & 1.1160 & 0.0154 & 1.0973 & 1.0797 & 0.0176 \\
$1986-1998$ & $(0.8602)$ & $(0.8574)$ & {$[2.53]$} & $(0.8441)$ & $(0.8302)$ & {$[2.45]$} \\
\hline \hline
\end{tabular}

This table reports the simple mean of TFP for groups of plants simulated to participate in the market using the estimated probit model reported in Columns (1) and (2) of Table 6. Standard deviations in parentheses in Columns (1), (2), (4) and (5); T statistics for mean differences in square brackets in Columns (4) and (6). The probability that a plant exits is estimated using actual values of all independent variables, including tariffs, in the results reported in Columns (1) and (4), while tariffs are set at their 1984 value in the results reported in Columns (2) and (5). Figures in Columns (1)-(3) include plants that entered after 1985, while Columns (4)-(6) only include plants present in 1985.

Table 8: Descriptive Statistics of Simulated TFP in 1998

\begin{tabular}{lcc}
\hline \hline & Actual Tariffs & 1984 Tariffs \\
& $(1)$ & $(2)$ \\
\cline { 2 - 3 } Mean & 1.1326 & 1.1050 \\
Standard Deviation & 0.9743 & 0.9495 \\
1st Percentile & -1.0934 & -1.1760 \\
50th Percentile & 1.1016 & 1.0985 \\
\hline \hline
\end{tabular}

This table reports descriptive statistics for the simulated distribution of TFP for 1998. The simulation uses actual tariffs in Column (1) and 1984 tariffs in Column (2). 
Table 9: Alternative Effects of Trade Reform on Aggregate and Plant-level

\section{Productivity.}

Panel 1:

Plant-level growth of TFP against the Change in Tariffs for the Plant's Sector

Change in tariffs

$-0.0747^{* * *}$

Sector effects

Year effects

4-digits

$\mathrm{R}^{2}$

Yes

$\mathrm{N}$

0.0129

56,113

Panel 2:

Plant-level Output Share in its 3-digit Sector against Tariffs for the Sector

$\begin{array}{lc}\text { TFP } & 0.3824^{* * *} \\ & (0.0161) \\ \text { Tariffs*TFP } & -0.1321^{* * *} \\ & (0.0194) \\ \text { Tariffs } & -0.0431 \\ & (0.0265) \\ \text { Sector effects } & \\ \text { Year effects } & \text { 3-digits } \\ \mathrm{R}^{2} & \text { Yes } \\ \mathrm{N} & 0.0773 \\ \end{array}$

Panel 3:

3-digit Sector Productivity against Tariffs for the Sector

Overall Sector Productivity

(1)

$-0.2051^{* *}$

Tariffs

Sector effects

Year effects

$\mathrm{R}^{2}$

$\mathrm{N}$
(0.0825)

3-digits
Yes
0.8268
336

OP Cross Term

(2)

$-0.1939^{* *}$

(0.0790)

3-digits
Yes
0.7779
336

Robust standard errors in parentheses. Panel 1 presents a regression at the plant level, controlling for sector effects (4-digit level) and for year effects. Panel 2 presents a plant-level regression of the share of sectoral output represented by the plant against the plant productivity, sectoral tariffs, and an interaction between productivity and tariffs, controlling for sector effects (3-digit level) and for year effects. Panel 3 presents are regressions at the 3-digit sector level, controlling for sector effects (3-digit level) and for year effects. Our industry productivity measure in Column (1) of panel 3 is the output-weighted plant-level log TFP and in Column (2) of that panel is the cross term of the Olley-Pakes decomposition of sector productivity. * indicates significance at the $10 \%$ level, ** indicates significance at the $5 \%$ level and *** indicates significance at the $1 \%$ level. 
Figure 1. Effective tariffs and reform index, 1984-1998

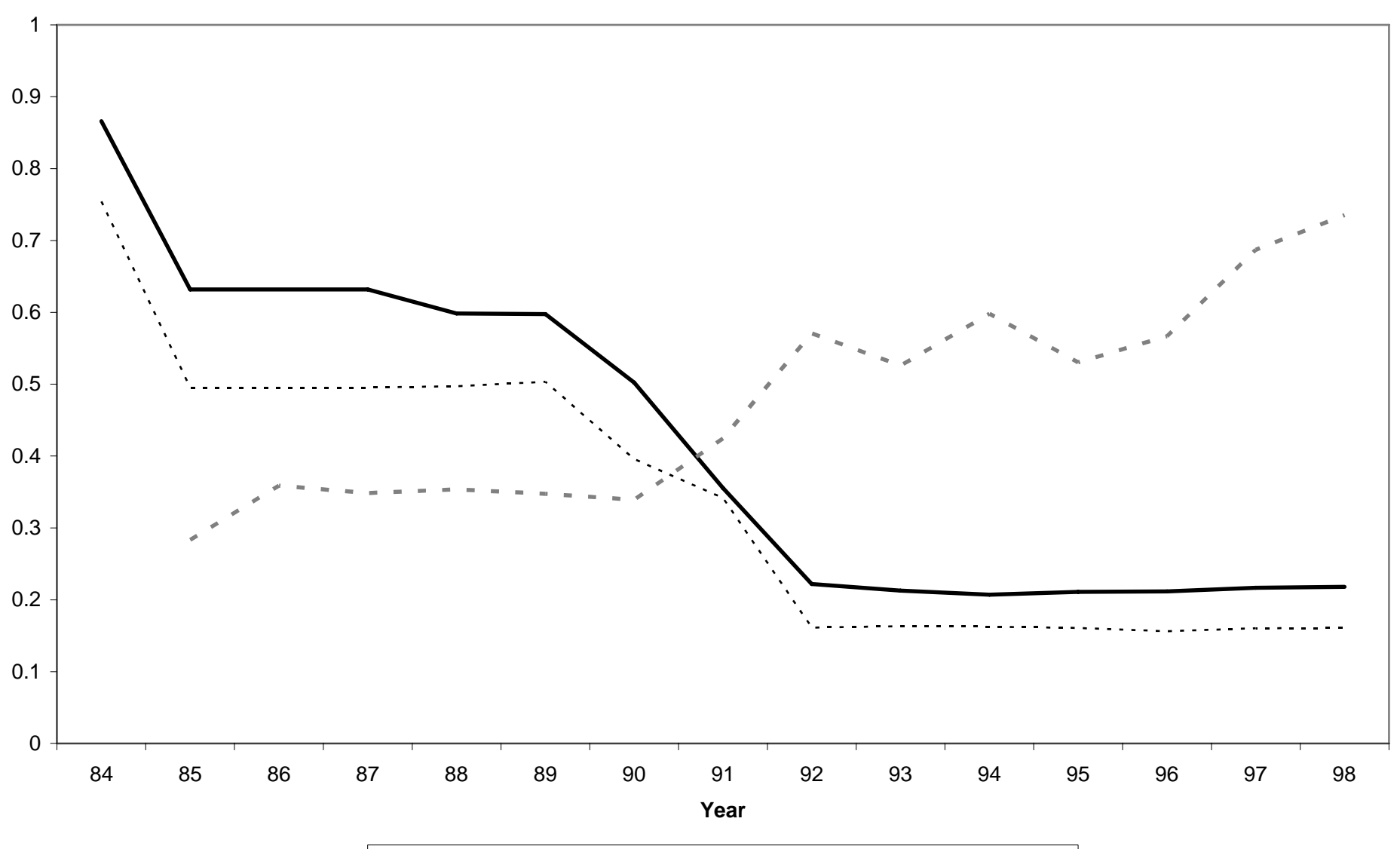

-Effective tariffs - . - . - St. dev. Effective tariffs = - = Reform Index 
Figure 2. Predicted exit probability: actual tariffs vs. 1984 tariffs

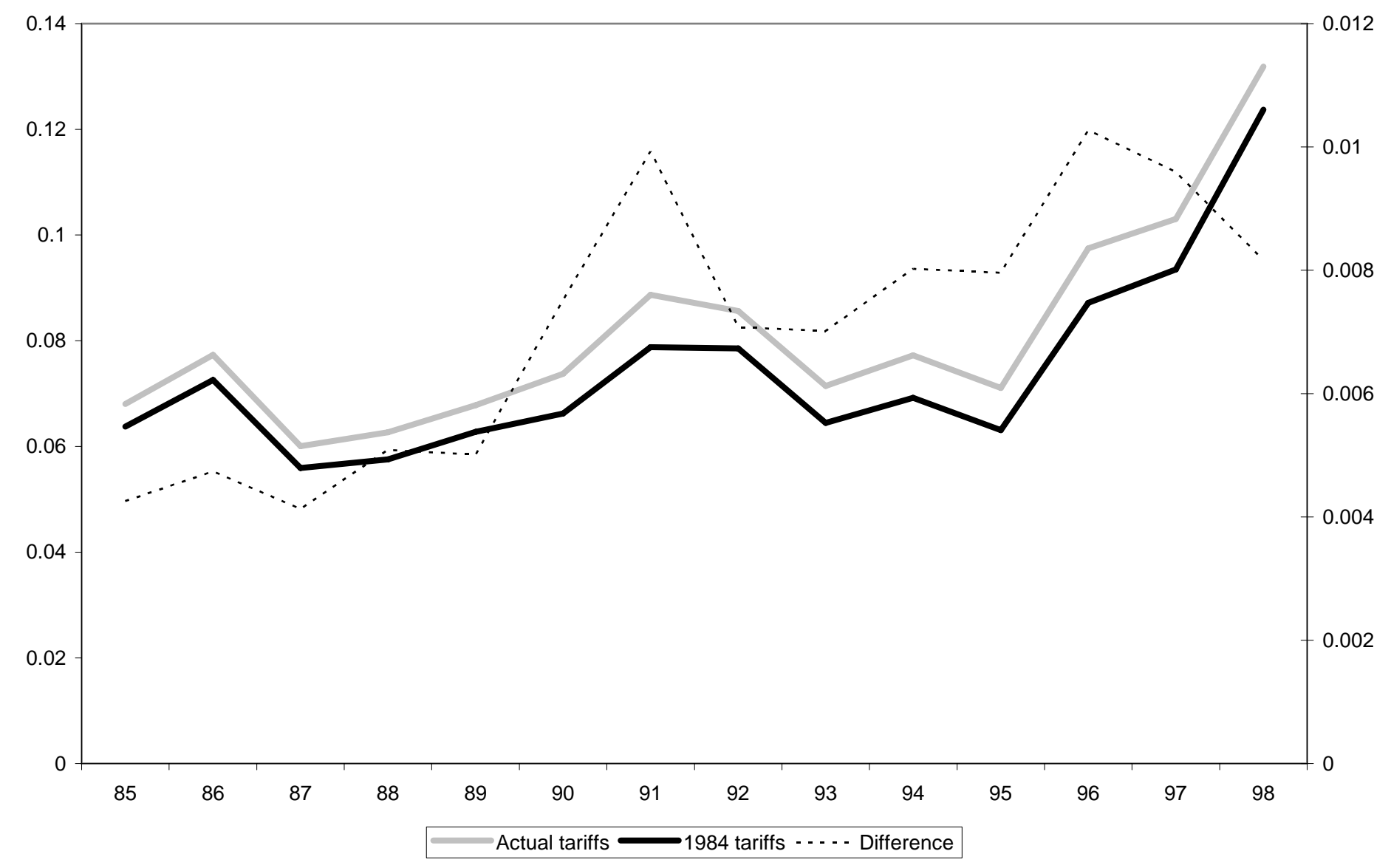

